\title{
a-Terpineol fumigation alleviates negative plant-soil feedbacks of Panax notoginseng via suppressing Ascomycota and enriching antagonistic bacteria
}

Chen Ye ${ }^{1 \dagger}$, Yixiang Liu ${ }^{1,2,3 \dagger}$, Junxing Zhang ${ }^{1}$, Tianyao $\mathrm{Li}^{4}$, Yijie Zhang ${ }^{1}$, Cunwu Guo ${ }^{1,3}$, Min Yang ${ }^{1,2,3}$, Xiahong He ${ }^{1,5}$, Youyong Zhu ${ }^{1,2,3}$, Huichuan Huang ${ }^{1,2,3^{*}}$ and Shusheng Zhu $^{1,2,3^{*}}$

\begin{abstract}
The accumulation of soil-borne pathogens is the main driving factor of negative plant-soil feedbacks (NPSFs), which seriously restricts the sustainable development of agriculture. Using natural volatile organic compounds (VOCs) from plants or microorganisms as biofumigants is an emerging strategy to alleviate NPSFs in an environmentally-friendly way. Here, we identified a-terpineol from the VOCs of pine needles, confirmed the ability of a-terpineol fumigation in alleviating the NPSF of Panax notoginseng via significantly reducing seed decay rate, and also deciphered the underlying mechanism by which the soil microbial community is modified. a-Terpineol fumigation could suppress culturable fungi but enrich bacteria in a dose-dependent manner. Network analysis with high-throughput sequencing data revealed that a-terpineol could distinctly modify both fungal and bacterial communities. In detail, a-terpineol significantly suppressed the relative abundance of Ascomycota from 64.04 to 32.26\%, but enriched the relative abundance of Proteobacteria, Acidobacteria and Actinobacteria. Subnetwork analysis further demonstrated that aterpineol could directly or indirectly suppress fungal pathogens and enrich plant growth-promoting rhizobacteria (PGPRs). In vitro fumigation and co-culture experiments with culturable isolates validated these findings. The antagonism between beneficial bacteria and pathogens, and the synergistic growth promotion among a-terpineolenriched bacteria might be involved in soil microbial community assembly. In summary, a-terpineol fumigation could directly or indirectly modify the soil microbial community to alleviate NPSFs, especially by suppressing fungal pathogens and enriching beneficial bacteria. This study suggests that VOCs from natural products are worth developing as biofumigants due to their multiple functions in modifying the soil microbial community.
\end{abstract}

Keywords: Negative plant-soil feedbacks, a-Terpineol, Soil-borne pathogens, Microbiome, Network analysis

\section{Background}

The processes by which plants alter the biotic and abiotic qualities of their living soils and cause positive or negative effects on the survival of themselves or their offspring are known as plant-soil feedbacks (PSFs)

\footnotetext{
*Correspondence: shushengzhu79@126.com; absklhhc@gmail.com

${ }^{+}$Chen Ye and Yixiang Liu contributed equally to this work.

'State Key Laboratory for Conservation and Utilization of Bio-Resources in

Yunnan, Yunnan Agricultural University, Kunming 650201, China

Full list of author information is available at the end of the article
}

(Kulmatiski et al. 2008; Bennett et al. 2017; Bennett and Klironomos 2019). Among PSFs, negative plant-soil feedbacks (NPSFs) usually play important roles in maintaining species diversity in natural system (Kulmatiski et al. 2008; Mangan et al. 2010; Lankau et al. 2011), whereas severely restrict the sustainable development of agricultural production, especially in monoculture cropping systems (Huang et al. 2013; Wei et al. 2018). Although some studies indicate that nutrient imbalance, the deterioration of soil physico-chemical properties and

(c) The Author(s). 2021 Open Access This article is licensed under a Creative Commons Attribution 4.0 International License, which permits use, sharing, adaptation, distribution and reproduction in any medium or format, as long as you give

appropriate credit to the original author(s) and the source, provide a link to the Creative Commons licence, and indicate if changes were made. The images or other third party material in this article are included in the article's Creative Commons licence, unless indicated otherwise in a credit line to the material. If material is not included in the article's Creative Commons licence and your intended use is not permitted by statutory regulation or exceeds the permitted use, you will need to obtain permission directly from the copyright holder. To view a copy of this licence, visit http://creativecommons.org/licenses/by/4.0/ 
the accumulation of autotoxins in rhizosphere soil lead to NPSFs, further evidence has demonstrated that imbalances in the rhizospheric microbiome, especially the build-up of soil-borne pathogens and the suppression of plant growth-promoting rhizobacteria (PGPRs), are the main reasons for NPSFs (Mangan et al. 2010; Yang et al. 2015; Wei et al. 2018; Yang et al. 2018a; Liu et al. 2019; Luo et al. 2019; Yang et al. 2019).

Methods to eliminate soil-borne pathogens, including steaming, microwave radiation, gamma irradiation, soil fumigants and fungicides, have been reported as effective ways to alleviate NPSFs (Alphei and Scheu 1993; Katan 2000; Miguel et al. 2004; Klose et al. 2006; Fennimore et al. 2014; Li et al. 2019; Yang et al. 2019). Among these methods, soil chemical fumigation is one of the most effective ways to control soil-borne diseases, which is attributable to the strong ability of the gases used to diffuse through the continuous soil air space, however, environmental unfriendliness has become the major limitation of this method (Lembright 1990; Chen et al. 2018). Although soil-borne pathogens are effectively killed, beneficial soil microorganisms are also suppressed due to the broad-spectrum antimicrobial activities of soil chemical fumigants (Podio et al. 2008; Wang et al. 2014; Gurtler 2017; Li et al. 2019; Yang et al. 2019). Moreover, soil-borne pathogens can quickly recolonize sterile soils in the absence of antagonism from beneficial microbes (Mendes et al. 2011; Yang et al. 2019). In addition, most soil treatment methods can be administered only before planting, which limits their application (Ibekwe et al. 2001; Gimsing and Kirkegaard 2006). Recently, many environmentally friendly fumigants have been developed and applied in the field (Gurtler 2017). Among them, soil biofumigations, which are based on the release of antipathogen volatiles from fresh plant residues (such as broccoli, cabbage and cauliflower) or microbes (such as Bacillus amyloliquefaciens and Streptomyces alboflavus), have been widely reported in controlling soil-borne diseases (NuñezZofío et al. 2012; Yuan et al. 2012; Arnault et al. 2013; Schalchli et al. 2016; Gurtler 2017; Yuan et al. 2017; Yang et al. 2018b; Jin et al. 2019; Zhang et al. 2020).

Sanqi (Panax notoginseng (Burk.) F. H. Chen), one of the most important Chinese medicinal plants, encounters NPSF-caused replant failure when it is successively planted in the same location (Yang et al. 2015). The build-up of soil-borne pathogens is the main cause of replant failure (Luo et al. 2019). Currently, a new cultivation model in coniferous forests has been developed to alleviate NPSF (Ye et al. 2019). Allelopathic interactions in forest cultivation mode, especially the volatile organic compounds (VOCs) released from pines and withered pine needles, can reduce disease damage by inducing plant SAR (systemic acquired resistance) or directly suppressing the growth of pathogens (Zheng 2008;
Riedlmeier et al. 2017). The VOCs emitted by pines or pine needles consist mainly of monoterpenes and alcohols, such as $\alpha$-pinene, $\beta$-pinene, germacrene $D$, myrcene, $\alpha$-terpineol and terpineol-4 (Ucar and Balaban 2004; Kim and Shin 2005; Park and Lee 2011; Politeo et al. 2011). Among them, $\alpha$-terpineol was reported to inhibit the growth of fungal pathogens by disrupting fungal cell membrane integrity (Park et al. 2009; Pinto et al. 2014; Zhou et al. 2014). However, whether $\alpha$ terpineol fumigation can alleviate the NPSFs involved in $P$. notoginseng cultivation and the underlying mechanisms remain unclear.

In this study, we used $\alpha$-terpineol as a biofumigant to treat soil in which a consecutive cultivation of $P$. notoginseng had been carried out, to (i) evaluate the effect of $\alpha$-terpineol fumigation on alleviating NPSF; (ii) characterize the impacts of $\alpha$-terpineol on soil bacterial and fungal community, as well as its dose effect; and (iii) explore the relationship between $\alpha$-terpineol fumigation, microbial community shifts and NPSF alleviation, and decipher the potential underlying mechanisms. We further validated the correlations of microbes shown in the co-occurrence network by in vitro fumigation or coculture. In brief, we expect to explore the mechanism by which $\alpha$-terpineol fumigation alleviates NPSFs.

\section{Results \\ a-Terpineol was detected in the volatile compounds released by pine needles}

The VOCs from pine needles of Pinus yunnanensis collected from three sites at different altitudes were analyzed by gas chromatography-mass spectrometry (GC-MS). $\alpha$ Terpineol was detected in all samples, with a MS (mass spectra) similarity higher than $90 \%$ (Fig. 1a-c) compared with the data in NIST14 library. The presence of $\alpha$ terpineol in pine needles was further verified by comparing the RT (retention time) and RI (retention index) with the synthetic standard sample of $\alpha$-terpineol (Fig. 1d).

\section{Alleviation of NPSFs by a-terpineol fumigation}

In pot experiments, the seed decay rate in soil with consecutive plantings of $P$. notoginseng reached $90.37 \%$ (Fig. 2). It was significantly decreased when the soil was fumigated with $50 \mu \mathrm{L} / \mathrm{L}$ of $\alpha$-terpineol for 4 weeks, with a value of $67.50 \%$ (Fig. 2). In contrast, the seed decay rate was significantly decreased to $13.28 \%$ after steam sterilization at $121^{\circ} \mathrm{C}$ for $15 \mathrm{~min}$ (Fig. 2). The results suggest that killing the soil-borne pathogens does alleviate NPSFs.

\section{a-Terpineol fumigation suppresses culturable fungi but enriches bacteria}

The number of culturable fungi was significantly decreased when consecutively planted soil was fumigated with an increasing concentration of $\alpha$-terpineol for 4 

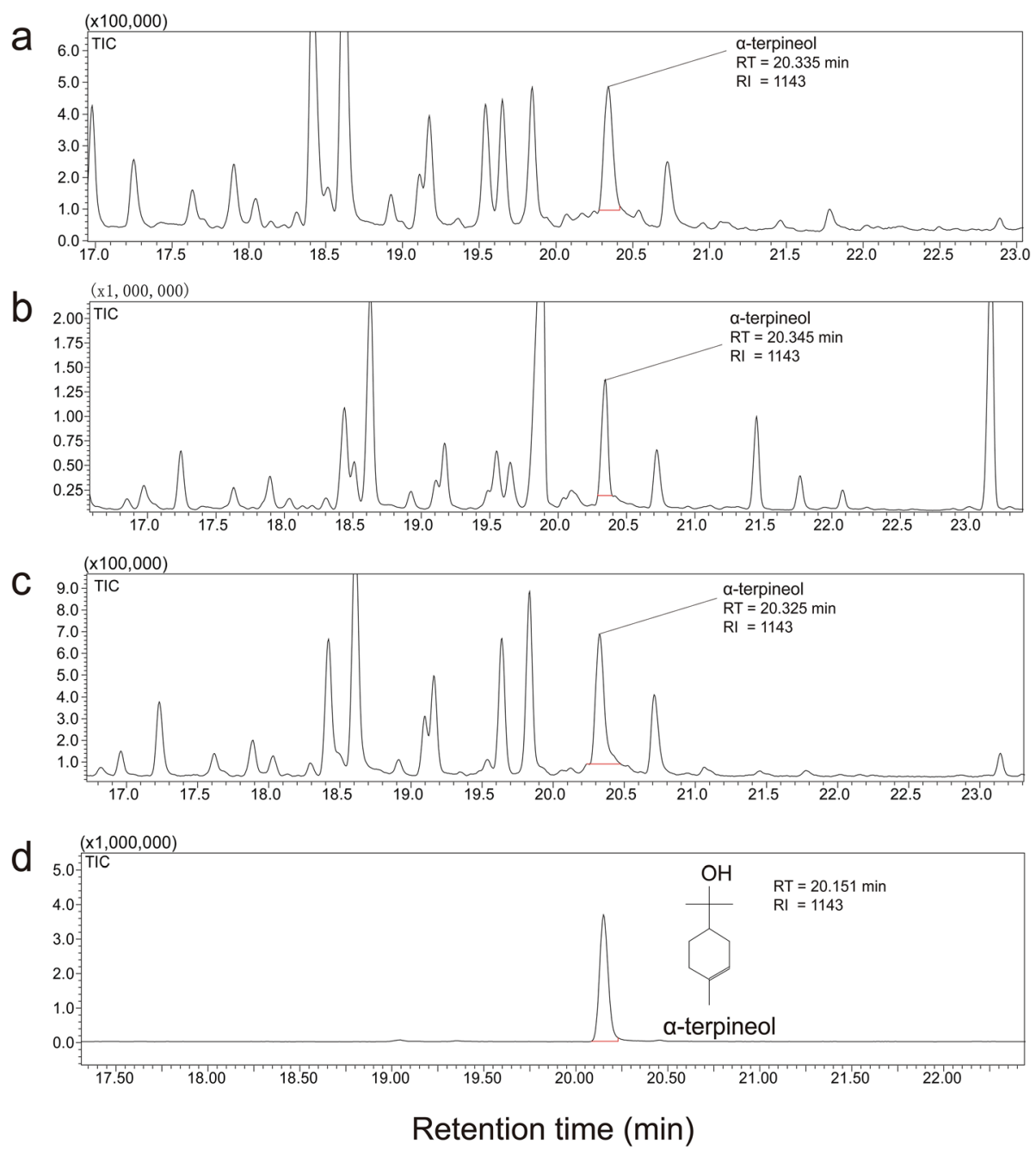

Fig. 1 Total ion current (TIC) chromatogram of VOCs emitted by pine needle powder of Pinus yunnanensis. a TIC chromatogram of the sample collected from Deqing County $\left(28^{\circ} 2^{\prime} 5^{\prime \prime} \mathrm{N}, 99^{\circ} 29^{\prime} 22^{\prime \prime} \mathrm{E}, 2860 \mathrm{~m}\right)$. b TIC chromatogram of the sample collected from Lijiang City $\left(26^{\circ} 57^{\prime} 16^{\prime \prime} \mathrm{N}, 100^{\circ} 3^{\prime}\right.$

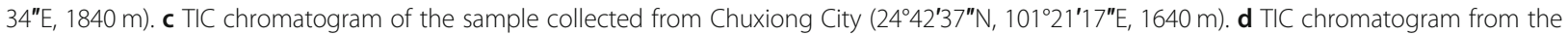
synthetic standard sample of a-terpineol. RT and RI indicate retention time and retention index, respectively

weeks (Fig. 3a), and the decrease in fungal number was dose-dependent (Pearson's $\mathrm{R}=-0.457, P<0.01$ ). However, the number of cultivable bacteria was significantly increased when fumigated with $\alpha$-terpineol at concentrations of 5,20 and $50 \mu \mathrm{L} / \mathrm{L}$ (Fig. $3 \mathrm{~b}$ ). Thus, the ratio of fungi to bacteria gradually decreased with increasing concentrations of $\alpha$-terpineol (Fig. 3c).

\section{a-Terpineol fumigation changes the diversity and composition of soil microbiome}

The consecutively planted soils fumigated with $\alpha$ terpineol at concentrations of $0,5,20$ and $50 \mu \mathrm{L} / \mathrm{L}$ were further analyzed with high-throughput sequencing technique to study the changes in fungal and bacterial communities. After filtering, a total of 1,408,373 high-quality reads of fungi were obtained from 12 samples, varying from 104,826 to 127,157 in each sample, and ultimately yielded 7029 OTUs (operational taxonomic units) with a cut-off level of 97\% similarity (Additional file 1: Table S1). For bacteria, we observed that the high abundance of Escherichia-Shigella (from 81.96 to $93.02 \%$ at the genus level) overshadowed the remaining microbial community (Additional file 2: Figure S1). Because of the weak correlation between Escherichia-Shigella and $\alpha$ terpineol (Pearson's $\mathrm{R}=0.114, P=0.724$ ), removing the sequence of Escherichia-Shigella did not influence the evaluation of $\alpha$-terpineol on microbial communities (Additional file 2: Figure S2). Accordingly, we eliminated Escherichia-Shigella sequences to gain more detailed insights into other microbial associates. Our EscherichiaShigella-free dataset contained a total of 431,237 highquality reads and yielded 3277 OTUs with a cut-off level 


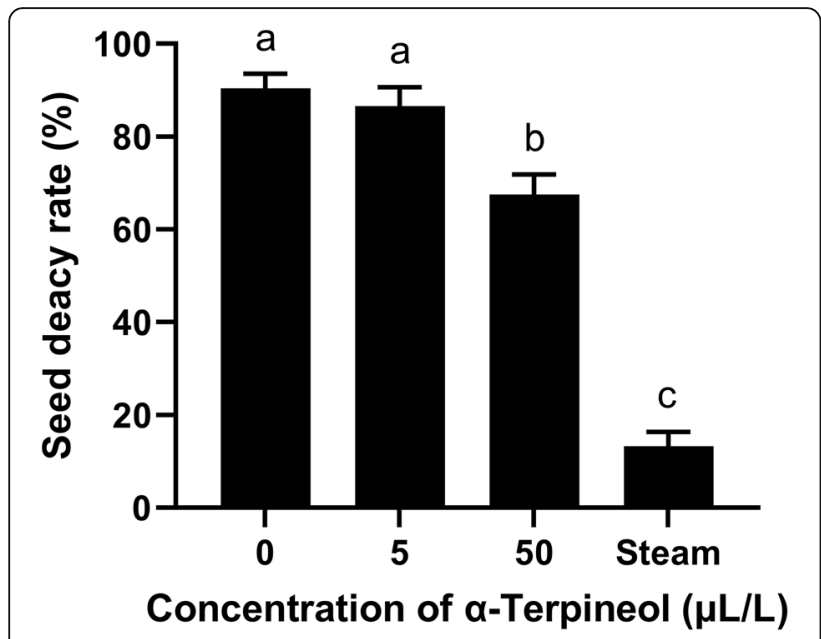

Fig. 2 Effects of a-terpineol fumigation on seed decay rate in soil consecutively planted with Panax notoginseng. The consecutively planted soil was fumigated with a-terpineol at concentrations of 0,5 and $50 \mu \mathrm{L} / \mathrm{L}$. Steam indicates treatment of soil with steam at $121^{\circ} \mathrm{C}$ for $15 \mathrm{~min}$, which was used as a positive control. Data are presented as the mean $\pm \mathrm{SE}$, bars indicate $\mathrm{SE}$, and different letters indicate significant differences analyzed by one-way ANOVA with Duncan's multiple range test, $P<0.05$

of $97 \%$ similarity for further analysis (Additional file 1 : Table S2).

Regarding the fungal community, the richness index (Chao1) first increased when soil fumigated with $5 \mu \mathrm{L} / \mathrm{L} \alpha-$ terpineol and then decreased when the concentration of $\alpha$ terpineol was increased to 20 or $50 \mu \mathrm{L} / \mathrm{L}$. However, the diversity index (Simpson) showed a significant dosedependent positive correlation with $\alpha$-terpineol (Pearson's $\mathrm{R}=0.697, P<0.05$ ) (Additional file 2: Figure S3). Regarding the bacterial community, there were no significant changes in the Chaol and Simpson indices with increasing concentrations of $\alpha$-terpineol (Additional file 2: Figure S3).
Principal coordinate analysis (PCoA) based on BrayCurtis distance indicated that both fungal (Fig. 4a) and bacterial communities (Fig. 4b) were clearly altered with increasing concentrations of $\alpha$-terpineol. The first axis explained more of the variation in fungal community than in bacterial community (Fig. 4a, b), which indicated the stronger effects of $\alpha$-terpineol fumigation on fungi. We further found that the fungal community treated by $0 \mu \mathrm{L} / \mathrm{L}$ of $\alpha$-terpineol was distinctly separated from that by 5,20 or $50 \mu \mathrm{L} / \mathrm{L}$ of $\alpha$-terpineol on the first axis, and also that by 5 or $20 \mu \mathrm{L} / \mathrm{L}$ of $\alpha$-terpineol on the second axis (Fig. 4a). The bacterial community treated by $0 \mu \mathrm{L} / \mathrm{L}$ of $\alpha$-terpineol was separated from that by 5 or $50 \mu \mathrm{L} / \mathrm{L}$ of $\alpha$-terpineol on the first axis, and by $5 \mu \mathrm{L} / \mathrm{L}$ of $\alpha$ terpineol on the second axis (Fig. 4b).

At the phylum level, Ascomycota dominated (64.04\%) the fungal community in the consecutively planted soil, followed by Rozellomycota (19.49\%) (Fig. 4c). When the consecutively planted soil was fumigated with $\alpha$ terpineol at 5,20 and $50 \mu \mathrm{L} / \mathrm{L}$, the relative abundance of Ascomycota was significantly decreased to $32.26-39.34 \%$ (Fig. 4c). The same trend was observed in Rozellomycota (11.20-17.33\%) (Fig. 4c). The decrease in Ascomycota and Rozellomycota was strongly dependent on the dose of $\alpha$-terpineol (Pearson's $\mathrm{R}=-0.719, P<0.01$ and Pearson's $\mathrm{R}=-0.701, P<0.05$, respectively) (Additional file 1 : Table S3). In the bacterial community, Proteobacteria (38.46\%), Bacteroidetes (30.40\%) and Firmicutes $(14.59 \%)$ occupied the dominant niches in the consecutively planted soil (Fig. 4d). However, there were no significant dose-dependent changes in most phyla upon $\alpha$ terpineol fumigation. Only weak positive correlations were observed in Proteobacteria, Acidobacteria, Epsilonbacteraeota, Planctomycetes and Actinobacteria with increasing concentrations of $\alpha$-terpineol (Additional file 1: Table S3).

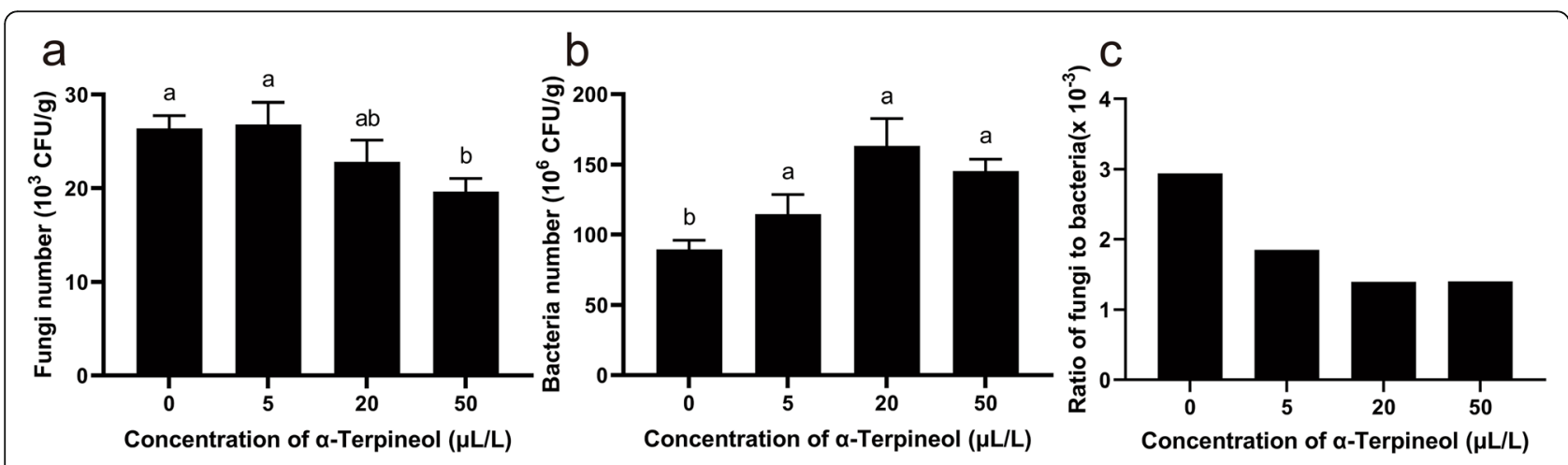

Fig. 3 Effects of a-terpineol fumigation on culturable fungi and bacteria in soil consecutively planted with Panax notoginseng. The numbers of culturable fungi (a) and bacteria (b) in soil fumigated with a-terpineol at concentrations of 0, 5, 20 or $50 \mu \mathrm{L} / \mathrm{L}$. c The ratios of fungi to bacteria in soil fumigated with a-terpineol at concentrations of 0, 5, 20 or $50 \mu \mathrm{L} / \mathrm{L}$. CFU, colony forming unit. Data are presented as the mean \pm SE, bars indicate $\mathrm{SE}$, and different letters indicate significant differences analyzed by one-way ANOVA with Duncan's multiple range test, $P<0.05$ 


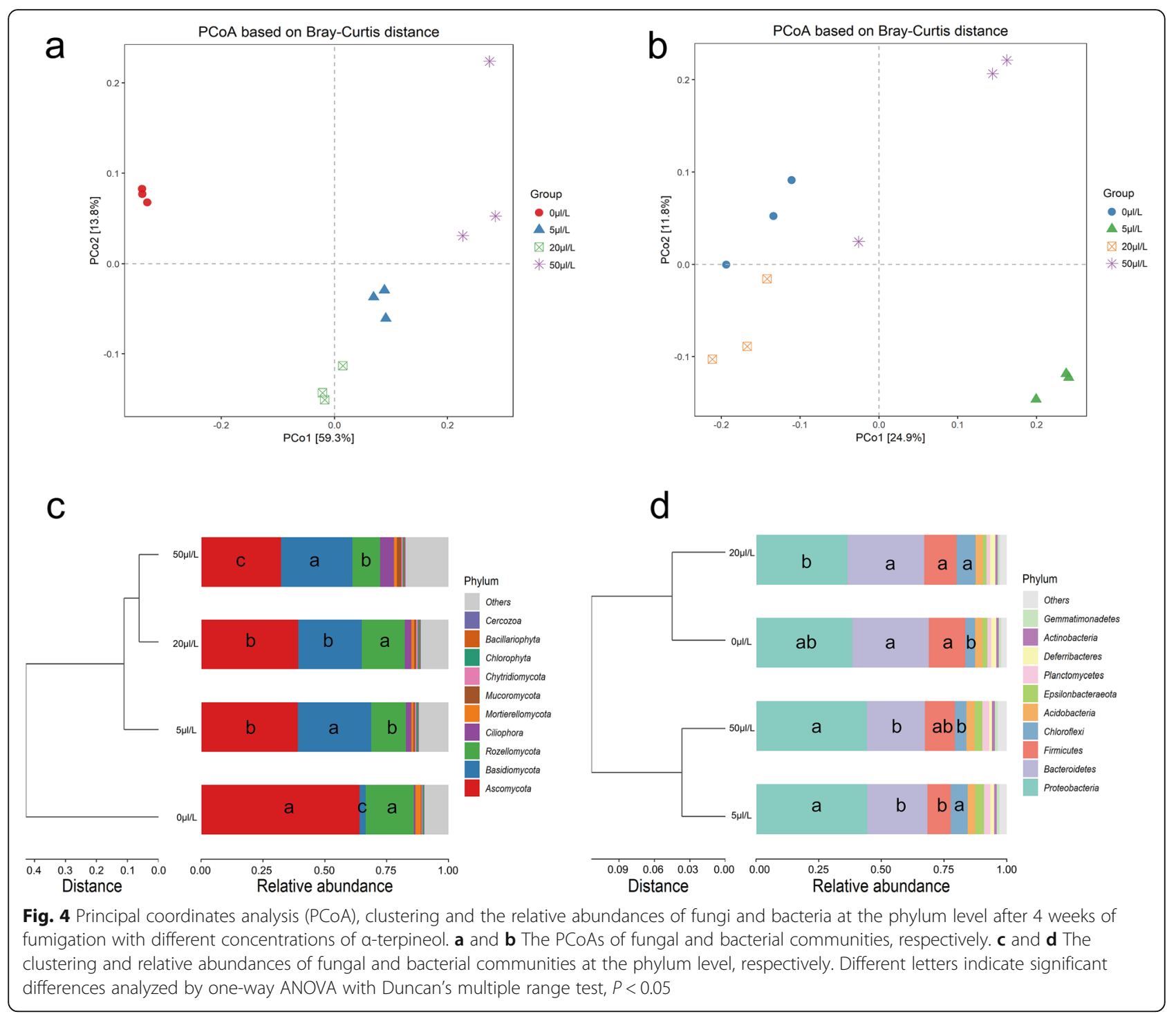

At the genus level, a total of 56 genera from fungi and bacteria were significantly correlated with the increase of $\alpha$-terpineol $(P<0.05)$, including 32 genera of fungi and 24 genera of bacteria (Fig. 5a). Among them, 37 genera were strongly positively correlated with the increase of $\alpha$-terpineol, of which 11 genera belonged to Proteobacteria (Fig. 5a). A total of 19 genera were significantly negatively correlated with the increase of $\alpha$-terpineol, of which 14 belonged to Ascomycota (Fig. 5a). These data further suggest that fungi (especially Ascomycota) are suppressed but bacteria (especially Proteobacteria) are selectively enriched by $\alpha$-terpineol fumigation.

\section{a-Terpineol fumigation modifies the soil microbial co- occurrence network}

The positive and negative co-occurrence networks were almost equal in size (the numbers of nodes were 335 and 343 , respectively) (Table 1 ). However, the positive network was more complex than the negative network (Fig. 5b, c), which reflected higher topological properties, including the total number of links (the edges between two nodes), average clustering coefficient (the higher connectedness among nodes in a particular region of a network), network density and average degree (the number of edges connected to a node) (Table 1).

In the positive network, genera belonging to Proteobacteria accounted for $26.57 \%$, followed by Ascomycota (24.18\%) and Firmicutes (11.04\%). However, genera of Ascomycota (32.94\%) dominated the negative network (Table 1). A node with a high degree (the number of edges connected to a node) is directly correlated with many nodes and is usually considered the keystone taxon of a complex network. Thus, we calculated the degrees of all nodes and 

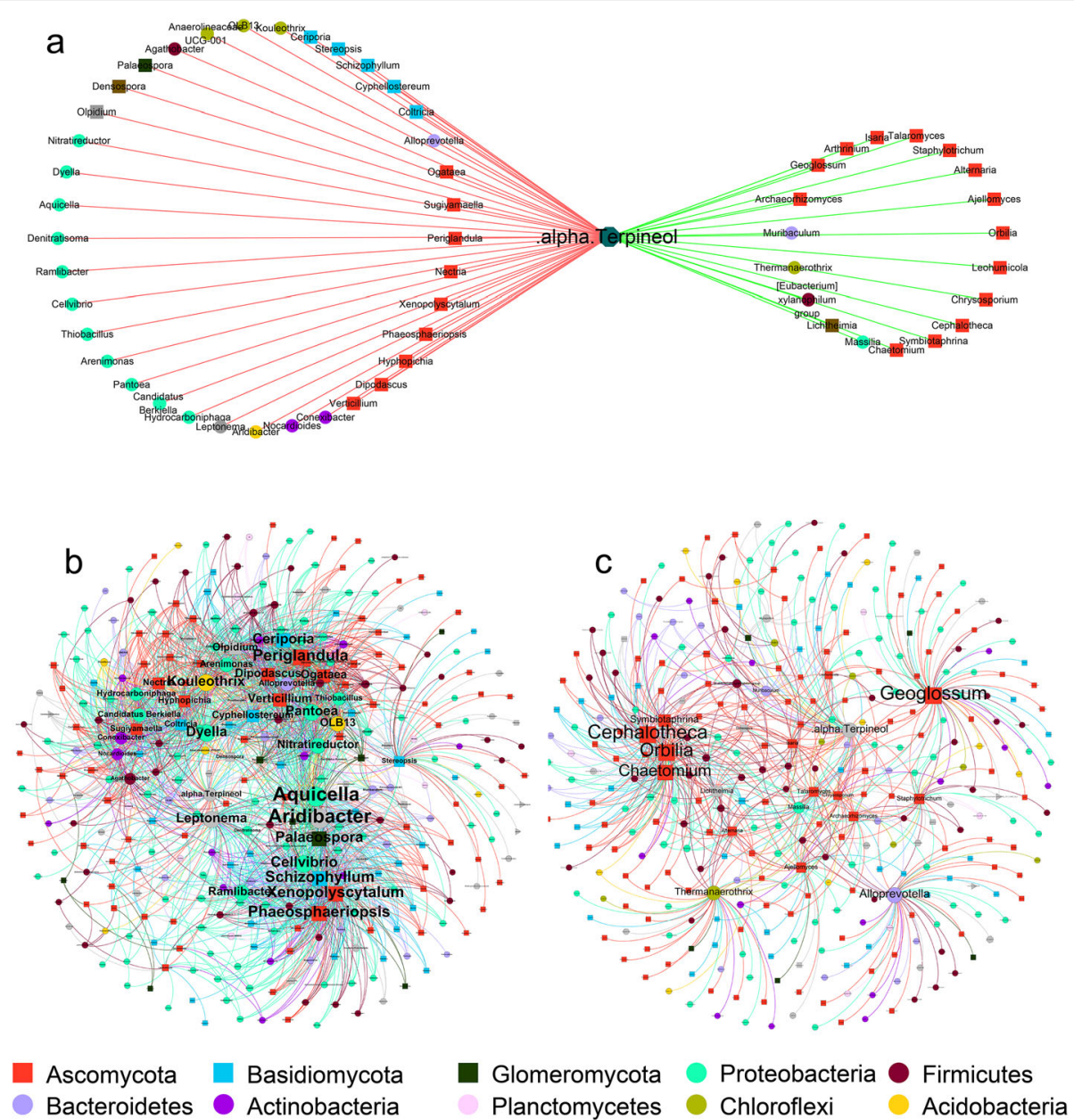

Fig. 5 Network analysis showing the correlations between a-terpineol and microbial communities. a Direct correlations between a-terpineol and fungi or bacteria at the genus level; red and green lines represent significant positive $(P<0.05)$ and negative $(P<0.05)$ linear relationships, respectively. $\mathbf{b}$ and $\mathbf{c}$ Co-occurrence networks between the 56 genera that were significantly correlated with a-terpineol (directly correlated) and other genera that were not significantly correlated with a-terpineol but significantly correlated with these 56 genera $(P<0.05$ and Pearson's $|R|>$ 0.6). The complicated co-occurrence network was divided into positive (b) and negative (c) networks according to the correlations of 56 genera with increasing concentrations of a-terpineol. Squares and circles represent fungi and bacteria, respectively. The size of a node and its label are proportional to the number of connections. Different phyla (nodes) use different colors, with the lines colored same as source nodes

further considered the top 10 genera with the highest degrees as the keystone taxa in the network (Table 1). Seven of the keystone taxa in the negative network and only two in the positive network belonged to Ascomycota (Table 1). Aquicella and Aridibacter showed the strongest connectivity in the positive network, with the highest degrees (Fig. 5b and Table 1).

\section{a-Terpineol fumigation directly or indirectly suppresses pathogens but enriches PGPRs}

The widely reported PGPRs (Additional file 1: Table S4) and soil-borne pathogens of $P$. notoginseng were highlighted in the $\alpha$-terpineol correlated subnetwork (Fig. 6). Alternaria, a potential soil-borne pathogen of $P$. notoginseng, was significantly negatively correlated with the concentration of $\alpha$-terpineol (Fig. 6). The common soil-borne pathogen Phytophthora showed a negative correlation with Alloprevotella, a bacteria positively correlated with $\alpha$-terpineol (Fig. 6). Another pathogen, Gibberella, showed positive correlations with Staphylotrichum and Geoglossum, which were significantly negatively correlated with $\alpha$-terpineol (Fig. 6). Thus, we inferred that these three potential soil-borne pathogens of $P$. notoginseng may have direct or indirect negative correlations with $\alpha$-terpineol. In contrast, many PGPRs showed direct or indirect positive correlations with $\alpha$ terpineol (Fig. 6). Among them, Pantoea, Thiobacillus, Nocardioides and Cellvibrio were directly positively correlated with $\alpha$-terpineol. Other PGPRs, including Azospirillum, Bacillus, Enterobacter, Aeromonas, Klebsiella, Stenotrophomonas, Frankia, Streptomyces, Enterococcus, 
Table 1 Topological properties in positive and negative co-occurrence networks

\begin{tabular}{|c|c|c|c|c|}
\hline Network topology parameters & \multicolumn{2}{|c|}{ Positive (including indirect positive) } & \multicolumn{2}{|c|}{ Negative (including indirect negative) } \\
\hline Total nodes & 335 & & 343 & \\
\hline Total links & 2341 & & 753 & \\
\hline Average clustering coefficient & 0.521 & & 0.321 & \\
\hline Network density & 0.042 & & 0.013 & \\
\hline Average degree & 13.976 & & 4.391 & \\
\hline \multirow[t]{8}{*}{ Percentage of top 10 phyla } & Fungi & Bacteria & Fungi & Bacteria \\
\hline & Ascomycota (24.18\%) & $\begin{array}{l}\text { Proteobacteria } \\
(26.57 \%)\end{array}$ & Ascomycota (32.94\%) & $\begin{array}{l}\text { Proteobacteria } \\
(21.28 \%)\end{array}$ \\
\hline & Basidiomycota (10.75\%) & Firmicutes (11.04\%) & Basidiomycota (9.91\%) & Firmicutes (12.54\%) \\
\hline & Glomeromycota (2.39\%) & $\begin{array}{l}\text { Bacteroidetes } \\
(5.67 \%)\end{array}$ & $\begin{array}{l}\text { Glomeromycota } \\
(1.46 \%)\end{array}$ & Bacteroidetes (5.25\%) \\
\hline & & $\begin{array}{l}\text { Actinobacteria } \\
(3.88 \%)\end{array}$ & & Actinobacteria (4.08\%) \\
\hline & & $\begin{array}{l}\text { Planctomycetes } \\
(3.58 \%)\end{array}$ & & Acidobacteria (2.62\%) \\
\hline & & Chloroflexi (2.09\%) & & Chloroflexi (2.33\%) \\
\hline & & $\begin{array}{l}\text { Acidobacteria } \\
(1.79 \%)\end{array}$ & & $\begin{array}{l}\text { Plantctomycetes } \\
(1.46 \%)\end{array}$ \\
\hline \multirow{9}{*}{$\begin{array}{l}\text { Keystone taxa (the numbers of degrees) [phylum } \\
\text { which the genus belong to] }\end{array}$} & Fungi & Bacteria & Fungi & Bacteria \\
\hline & $\begin{array}{l}\text { Periglandula (92) } \\
\text { [Ascomycota] }\end{array}$ & $\begin{array}{l}\text { Aquicella (105) } \\
\text { [Proteobacteria] }\end{array}$ & $\begin{array}{l}\text { Cephalotheca (71) } \\
\text { [Ascomycota] }\end{array}$ & $\begin{array}{l}\text { Alloprevotella (50) } \\
\text { [Bacteroidetes] }\end{array}$ \\
\hline & $\begin{array}{l}\text { Phaeosphaeriopsis (90) } \\
\text { [Ascomycota] }\end{array}$ & $\begin{array}{l}\text { Aridibacter (105) } \\
\text { [Acidobacteria] }\end{array}$ & $\begin{array}{l}\text { Geoglossum (70) } \\
\text { [Ascomycota] }\end{array}$ & $\begin{array}{l}\text { Thermanaerothrix (44) } \\
\text { [Chloroflexi] }\end{array}$ \\
\hline & $\begin{array}{l}\text { Ceriporia (84) } \\
\text { [Basidiomycota] }\end{array}$ & $\begin{array}{l}\text { Cellvibrio (87) } \\
\text { [Proteobacteria] }\end{array}$ & $\begin{array}{l}\text { Orbilia (69) } \\
\text { [Ascomycota] }\end{array}$ & \\
\hline & $\begin{array}{l}\text { Schizophyllum (90) } \\
\text { [Basidiomycota] }\end{array}$ & $\begin{array}{l}\text { Dyella }(84) \\
\text { [Proteobacteria] }\end{array}$ & $\begin{array}{l}\text { Chaetomium (63) } \\
\text { [Ascomycota] }\end{array}$ & \\
\hline & $\begin{array}{l}\text { Palaeospora (87) } \\
\text { [Glomeromycota] }\end{array}$ & $\begin{array}{l}\text { Kouleothrix (84) } \\
\text { [Chloroflexi] }\end{array}$ & $\begin{array}{l}\text { Symbiotaphrina (44) } \\
\text { [Ascomycota] }\end{array}$ & \\
\hline & & & $\begin{array}{l}\text { Staphylotrichum (31) } \\
\text { [Ascomycota] }\end{array}$ & \\
\hline & & & $\begin{array}{l}\text { Lichtheimia (32) } \\
\text { [Mucoromycota] }\end{array}$ & \\
\hline & & & $\begin{array}{l}\text { Ajellomyces (31) } \\
\text { [Ascomycota] }\end{array}$ & \\
\hline
\end{tabular}

Acinetobacter, Allorhizobium-Neorhizobium-Pararhizobium-Rhizobium and Burkholderia-Caballeronia-Paraburkholderia, showed indirect positive correlations with $\alpha$-terpineol (Fig. 6). We further found that all these enriched PGPRs showed a negative correlation with the abovementioned three pathogens, i.e. Gibberella, Phytophthora and Alternaria (Fig. 6). Among them, Bacillus and Ramlibacter were significantly negatively correlated with Alternaria (Fig. 6).

To validate the effects of $\alpha$-terpineol on microbes, we investigated the antimicrobial activities of $\alpha$-terpineol against five soil-borne pathogens of $P$. notoginseng by in vitro fumigation test. The results showed that the mycelial growth of these five pathogens was inhibited by increasing concentrations of $\alpha$-terpineol (Fig. 7a). Based on the effective concentration for $50 \%$ inhibition $\left(\mathrm{EC}_{50}\right)$, we found that Phytophthora cactorum was strongly inhibited by $\alpha$-terpineol with an $\mathrm{EC}_{50}$ of $22.50 \mu \mathrm{L} / \mathrm{L}$, followed by Alternaria panax, Ilyonectria destructans and Fusarium oxysporum with $\mathrm{EC}_{50}$ values of 57.16, 66.63 and $106.59 \mu \mathrm{L} / \mathrm{L}$, respectively. Fusarium solani was less sensitive to $\alpha$-terpineol than the other four pathogens but was also inhibited strongly (with an $\mathrm{EC}_{50}$ value of $305.55 \mu \mathrm{L} / \mathrm{L}$ ). To validate the effects of $\alpha$-terpineol on other culturable non-pathogenic fungi, we obtained 23 fungal isolates belonging to 8 genera from consecutively planted soil of $P$. notoginseng (Additional file 1: Table S5). Among them, six non-pathogenic fungal isolates identified as Chaetomium globosum, Talaromyces flavus, Fusarium redolens and Fusarium graminearum were all 


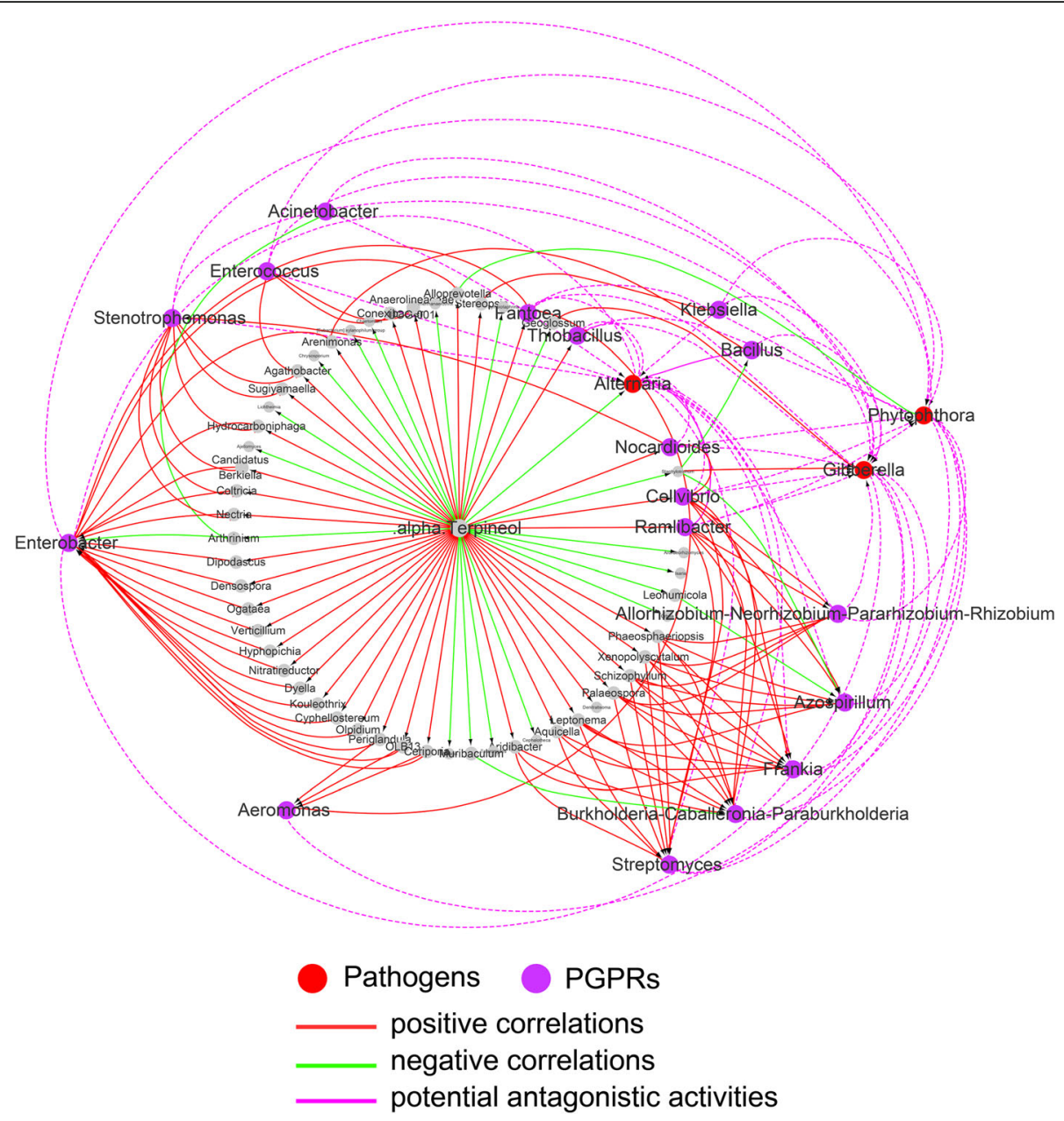

Fig. 6 Subnetwork of 56 genera of fungi and bacteria directly or indirectly correlated with the increase of a-terpineol, including fungal pathogens and previously isolated or widely reported PGPRs. Purple and red circles represent PGPRs and pathogens, respectively. Red and green lines indicate positive and negative correlations, respectively. The purple line represents the potential antagonistic activities of PGPRs against pathogens. Solid and dotted lines indicate significant and nonsignificant correlations, respectively

inhibited by increasing concentrations of $\alpha$-terpineol with $\mathrm{EC}_{50}$ values of $164.31,63.99,41.46,42.40,79.12$ and $31.93 \mu \mathrm{L} / \mathrm{L}$, respectively (Additional file 2: Figure S4).

A total of 189 bacterial isolates belonging to 26 genera (Additional file 1: Table S6) were isolated from consecutively planted soil, including those from Nocardioides, Ramlibacter, Stenotrophomonas, Burkholderia, Streptomyces, Bacillus and Rhizobium (Additional file 1: Table S7), which showed direct or indirect positive correlations with $\alpha$-terpineol in the subnetwork and were further selected to verify their correlations. Nocardioides, which showed a direct positive relationship with $\alpha$-terpineol (Fig. 6), was significantly promoted by in vitro fumigation with $\alpha$-terpineol at concentrations of 5, 10 and $20 \mu \mathrm{L} / \mathrm{L}$ (Fig. 7b). However, in vitro fumigation with $\alpha-$ terpineol did not promote the growth of Ramlibacter but showed only weak inhibition (Fig. 7b). In addition, a synergistic effect on growth promotion between Stenotrophomonas and Nocardioides, and between Streptomyces and Ramlibacter was demonstrated when the colonies of two strains got more closer in in vitro coculture (Fig. 8), which was consistent with the correlations in the co-occurrence network (Fig. 6). Furthermore, we found that the isolates from Nocardioides, Ramlibacter, Burkholderia, Streptomyces and Bacillus exhibited antagonistic activities against five soil-borne pathogens of $P$. notoginseng (Table 2), which further confirmed the antagonistic activities of those $\alpha$ terpineol-enriched PGPRs in the subnetwork (Fig. 6).

\section{Discussion}

NPSFs seriously limit the sustainable development of agricultural production. The core factor in NPSF is the build-up of soil-borne pathogens (Huang et al. 2013; Wei et al. 2018; Luo et al. 2019). Many physical or 


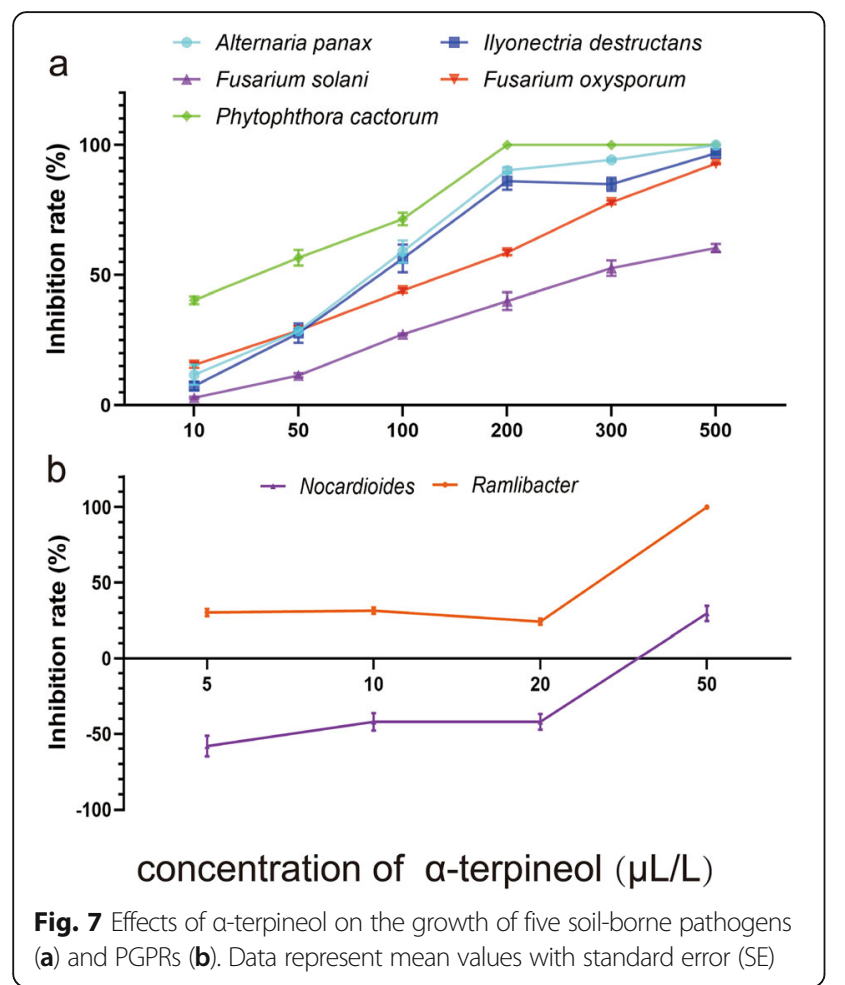

chemical treatments can completely kill all microorganisms in the soil to eliminate NPSF but usually face the problem of rapid recolonization by soil-borne pathogens (Mendes et al. 2011; Le Cointe et al. 2016; Gurtler 2017; Kumar et al. 2017; Li et al. 2019; Yang et al. 2019). Encouragingly, soil biofumigation is an emerging strategy to alleviate NPSF by targeted antagonism of plant pathogens or to regulate soil microbial communities (Omirou et al. 2011; Nuñez-Zofío et al. 2012; Wang et al. 2014). Here, we found that $\alpha$-terpineol, a natural volatile monoterpene alcohol released by pine needles, could alleviate the NPSF of $P$. notoginseng by directly or indirectly suppressing the relative abundance of soil-borne fungi (especially Ascomycota), including fungal pathogens, and enriching beneficial bacteria in soil microbial communities.

a-Terpineol fumigation alleviates NPSF by modifying the microbial community

The cultivation of $P$. notoginseng is seriously limited by NPSF, which is reflected in the build-up of soil-borne pathogens and gradually increased infection of the plant
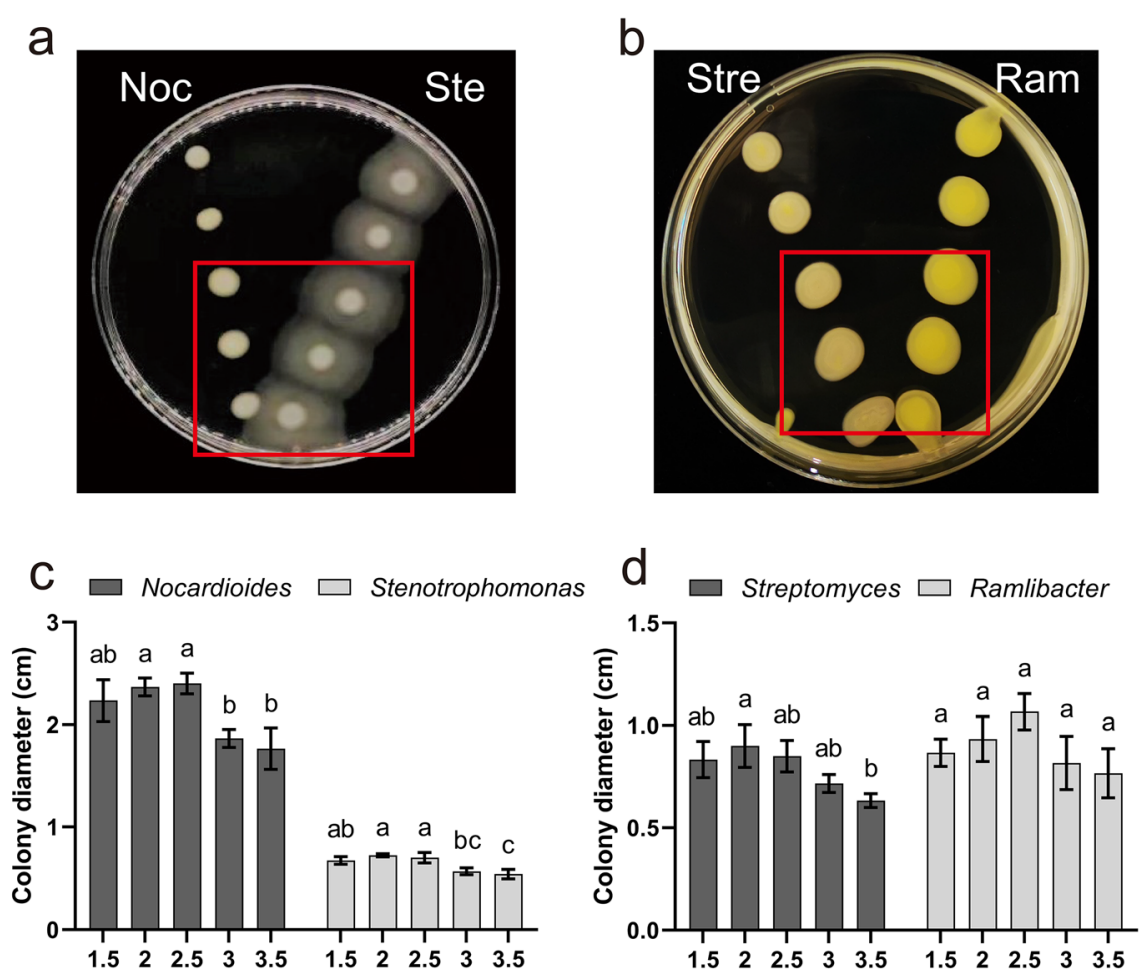

The distance between two bacterial strains $(\mathrm{cm})$ The distance between two bacterial strains $(\mathrm{cm})$

Fig. 8 Validation of network correlations under a-terpineol fumigation. a and $\mathbf{c}$ The synergistic effects of growth promotion between Nocardioides (directly enriched by a-terpineol) and Stenotrophomonas (indirectly enriched by a-terpineol). $\mathbf{b}$ and $\mathbf{d}$ The synergistic effects of growth promotion between Ramlibacter (directly enriched by a-terpineol) and Streptomyces (indirectly enriched by a-terpineol). Data are presented as the mean $\pm \mathrm{SE}$, bars indicate $\mathrm{SE}$, and different letters indicate significant differences analyzed by one-way ANOVA with Duncan's multiple range test, $P<0.05$. Noc, Nocardioides; Ste, Stenotrophomonas; Stre, Streptomyces; Ram, Ramlibacter 
Table 2 Antagonistic effect of bacterial isolates against the soil-borne fungal pathogens of Panax notoginseng

\begin{tabular}{|c|c|c|c|c|c|}
\hline \multirow[t]{2}{*}{ Isolate } & \multicolumn{5}{|c|}{ Inhibition rate (\%) } \\
\hline & A. panax & I. destructans & F. solani & F. oxysporum & P. cactorum \\
\hline Nocardioides & $34.83 \pm 0.92$ & $46.83 \pm 1.03$ & $28.27 \pm 0.62$ & $47.16 \pm 0.93$ & - \\
\hline Ramlibacter & $46.30 \pm 0.71$ & - & $43.49 \pm 1.73$ & - & $34.32 \pm 7.69$ \\
\hline Stenotrophomonas & - & $46.84 \pm 2.83$ & - & $23.23 \pm 1.01$ & - \\
\hline Burkholderia & $42.22 \pm 1.65$ & $37.50 \pm 7.48$ & $43.43 \pm 0.52$ & $51.44 \pm 1.55$ & $46.86 \pm 1.31$ \\
\hline Streptomyces & $47.16 \pm 1.10$ & - & - & - & $27.85 \pm 0.99$ \\
\hline Rhizobium & - & - & - & - & - \\
\hline Bacillus & $42.84 \pm 1.06$ & $39.89 \pm 1.02$ & $47.85 \pm 1.44$ & - & $77.70 \pm 0.4$ \\
\hline
\end{tabular}

A. panax, Alternaria panax; I. destructans, llyonectria destructans; F. oxysporum, Fusarium oxysporum; F. solani, Fusarium solani; P. cactorum, Phytophthora cactorum.

"-" indicates that there is no antagonistic effect between two strains

by these pathogens (Wei et al. 2018; Yang et al. 2019). Our pot experiments demonstrated that $\alpha$-terpineol fumigation of soil consecutively planted with $P$. notoginseng could significantly decrease seed decay (Fig. 2). Further study revealed that soil culturable fungi were significantly suppressed by $\alpha$-terpineol fumigation in a dose-dependent manner, but culturable bacteria were enriched (Fig. 3). Consistently, high-throughput sequencing analysis confirmed that fungi were more sensitive to $\alpha$-terpineol than bacteria based on the changes in relative abundance (Fig. 4c, d), richness and diversity indices (Additional file 2: Figure S3) and PCoA (Fig. 4a, b). Moreover, in vitro fumigation experiments indicated that $\alpha$-terpineol showed broad-spectrum antifungal activities (Fig. 7a and Additional file 2: Figure S4) but only weak antibacterial activities, even directly promoting the growth of some bacteria, such as Nocardioides (Fig. 7b). Thus, these data demonstrated that $\alpha$-terpineol fumigation could selectively suppress fungi but enrich bacteria to shift unity from a fungal-dominant to a bacterialdominant soil microbial community. Previous reports have shown that a fungal-dominant microbial community can aggravate the root rot of $P$. notoginseng (Wei et al. 2018; Luo et al. 2019). In contrast, many researchers have reported that an increase in the relative abundance of bacteria, especially antagonistic bacteria, can significantly reduce the harm of pathogens (Latz et al. 2012; Mendes et al. 2018; Wei et al. 2019), even forming disease-suppressive soil to protect plant health (Mendes et al. 2011; Cha et al. 2016; Siegel-Hertz et al. 2018). Likewise, a bacteria-dominant microbial community has advantages for microbial interactions and may favor bacteria-driven soil nutrient cycling (Bahram et al. 2018). Therefore, $\alpha$-terpineol fumigation could alleviate NPSF by changing soil microbial structure and function. This feature can help to avoid the disadvantages caused by soil chemical fumigation (Ibekwe et al. 2001; Gurtler 2017; Chen et al. 2018). Additionally, the enrichment of PGPRs by $\alpha$-terpineol fumigation could remove the barrier of deficient colonization by artificially inoculated PGPRs in the soil (Gómez Expósito et al. 2017).

\section{a-Terpineol fumigation suppresses fungal pathogens in Ascomycota to alleviate NPSF}

Several previous studies demonstrated that most soilborne pathogens, such as Alternaria, Fusarium and Cylindrocarpon, which belong to Ascomycota, could be enriched in the rhizosphere of $P$. notoginseng and ultimately cause severe NPSFs (Miao et al. 2006; Mao et al. 2014; Wei et al. 2018; Luo et al. 2019). Our data indicated that Ascomycota dominated the fungal community in consecutively planted soil but showed a significant dose-dependent decrease when the consecutively planted soil was fumigated with $\alpha$-terpineol (Fig. 4c). Further network analysis suggested that the nodes belonging to Ascomycota dominated the negative microbial cooccurrence network (Fig. 5c and Table 1). Likewise, keystone taxa are usually regarded as hubs of a network and can be considered drivers of microbiome structure and function (Banerjee et al. 2018; Hartman et al. 2018; Banerjee et al. 2019). In this study, we found that 7 out of 10 keystone taxa of the negative network belonged to Ascomycota (Table 1). These results further indicated that Ascomycota was suppressed by $\alpha$-terpineol fumigation.

Furthermore, we observed that the potential pathogen Alternaria showed a direct negative correlation and the pathogens Gibberella and Phytophthora exhibited indirect negative correlations with $\alpha$-terpineol in the network (Fig. 6). The in vitro antifungal tests confirmed that $\alpha$ terpineol could inhibit the growth of five soil-borne pathogens of $P$. notoginseng, four of which belong to Ascomycota (Fig. 7a). In addition, six non-pathogenic fungi belonging to Ascomycota were also inhibited by $\alpha$ terpineol in a dose-dependent manner (Additional file 2: Figure S4). This was consistent with previous reports that $\alpha$-terpineol showed antifungal activity against Ascomycota (Hammer et al. 2003; Pinto et al. 2014; Zhou 
et al. 2014). Although $\alpha$-terpineol was previously reported to disrupt the cell membrane integrity of Geotrichum citriaurantii (Zhou et al. 2014) and trigger the programmed cell death of Chlamydomonas reinhardtii by increasing reactive oxygen species (ROS) (Chen et al. 2019), the antifungal mechanisms of $\alpha$-terpineol remain worthy of further study.

\section{a-Terpineol directly or indirectly enriches beneficial bacteria to antagonize soil-borne pathogens}

With the occurrence of NPSF, the abundance of Acidobacteria, Planctomycetes and Actinobacteria was significantly suppressed in the rhizosphere of $P$. notoginseng (Luo et al. 2019). Here, we found that Acidobacteria, Planctomycetes and Actinobacteria could be enriched by $\alpha$-terpineol fumigation (Additional file 1: Table S3). Isolates from these phyla are widely used to protect crops from diseases and to decompose cellulose (Loqman et al. 2009; Eichorst et al. 2011; Sathya et al. 2017). Moreover, based on network analysis, we found that a total of 20 genera, mainly Proteobacteria, were significantly enriched by $\alpha$-terpineol (Fig. 5a). Network analysis also demonstrated that Proteobacteria dominated the positive network, and Aquicella, Cellvibrio and Dyella, which belong to Proteobacteria, were identified as keystone taxa in the microbial network (Table 1).

The subnetwork analysis subsequently showed that $\alpha$ terpineol not only directly modified bacteria but also indirectly enriched many PGPRs through these directly modified bacteria (Fig. 6). Among these bacteria directly or indirectly modified by $\alpha$-terpineol, there were many well documented PGPRs, such as Nocardioides, Pantoea, Thiobacillus, Cellvibrio, Stenotrophomonas, Burkholderia, Streptomyces, Bacillus and Rhizobium, which play important roles as antagonists against pathogens, producing phytohormone auxins, improving soil fertility and so on (El-Azeem et al. 2007; Mishra et al. 2011; Ullah et al. 2013; Pii et al. 2015; Vejan et al. 2016; Besharati 2017) (Fig. 6). Network analysis further suggested that these enriched PGPRs showed potential antagonistic activities, which were reflected in the negative correlations with pathogens in the subnetwork (Fig. 6), and the strong antagonistic activity against pathogens shown by these isolates from Nocardioides, Ramlibacter, Burkholderia, Streptomyces and Bacillus subsequently verified these correlations (Table 2).

Hassani et al. (2018) and Durán et al. (2018) reported that microbe-microbe interactions are important for the establishment and maintenance of the host-microbiota balance as well as improving plant host survival. Through the subnetwork analysis, we further found that $\alpha$-terpineol could modify the assemblages of the soil microbial community to enrich PGPRs by directly or indirectly affecting the interactions of microbes. First, $\alpha$ - terpineol could directly promote the growth of some PGPRs. This was confirmed by the effect of in vitro $\alpha$ terpineol fumigation on Nocardioides, which showed positive correlations with $\alpha$-terpineol (Fig. 7b). Second, $\alpha$-terpineol could affect interkingdom interactions to modify the microbial community. Recent evidence has indicated that microbial interkingdom interactions play critical roles in shaping soil microbial communities (Bahram et al. 2018; D'Souza et al. 2018; Finkel et al. 2019) and can typically be classified as antagonistic, neutral, and beneficial (Little et al. 2008; D'Souza et al. 2018). In this study, we found that Ramlibacter showed direct positive correlations with $\alpha$-terpineol in network analyses (Fig. 6), but $\alpha$-terpineol in vitro fumigation did not show a direct effect on the growth of Ramlibacter. Due to the strong antagonistic interactions between Ramlibacter and soil-borne fungal pathogens (Table 2), the antagonistic interactions might be weakened, resulting in the enrichment of Ramlibacter when the fungi suffered broad-spectrum suppression under $\alpha$-terpineol fumigation. Likewise, Agler et al. (2016) previously reported that some fungal hub microbes could control the abundance of bacteria by suppressing the growth and diversity of other microbes. However, this relationship still needs to be further verified. Third, $\alpha$-terpineol could indirectly recruit PGPRs. In this study, we found that although $\alpha$-terpineol cannot directly modify most PGPRs, V-shaped co-culture experiments showed that microbes that were significantly positively correlated with $\alpha$ terpineol could promote the growth of many PGPRs (Fig. 8). However, the mechanisms of this synergistic assembly of PGPRs under $\alpha$-terpineol fumigation need further study. Encouragingly, cross-feeding interactions, in which bacteria frequently exchange metabolites such as vitamins, amino acids, nucleotides or growth factors (D'Souza et al. 2018), provided clues for further verification.

\section{Conclusions}

Our results showed that $\alpha$-terpineol fumigation could alleviate NPSF of $P$. notoginseng by rebalancing soil microbial communities, and this was mainly reflected by the inhibition of soil-borne fungal pathogens and the enrichment of PGPRs. The enrichment of PGPRs exerted strong antagonistic activity to soil-borne pathogens of $P$. notoginseng, which might play an important role in the maintenance of soil health during the growth of $P$. notoginseng. Thus, $\alpha$ terpineol can be used as a soil biofumigant, as well as a microbial community improver, to reduce the impact of NPSFs in an environmental-friendly mode.

\section{Methods}

\section{VOC detection and a-terpineol identification}

Fresh pine needles of $P$. yunnanensis were collected from pine trees in Deqin County (Yunnan Province, China, 
$28^{\circ} 2^{\prime} 5^{\prime \prime} \mathrm{N}, 99^{\circ} 29^{\prime} 22^{\prime \prime} \mathrm{E}, 2860 \mathrm{~m}$ ), Lijiang City (Yunnan Province, China, 26 $\left.57^{\prime} 16^{\prime \prime} \mathrm{N}, 100^{\circ} 3^{\prime} 34^{\prime \prime} \mathrm{E}, 1840 \mathrm{~m}\right)$ and Chuxiong City (Yunnan Province, China, $24^{\circ} 42^{\prime} 37^{\prime \prime} \mathrm{N}$, $\left.101^{\circ} 21^{\prime} 17^{\prime \prime} \mathrm{E}, 1640 \mathrm{~m}\right)$. The dried pine needles were made into powder, and VOCs were extracted for $48 \mathrm{~h}$ through a "push-pull" system previously reported by Berhal et al. (2017). Briefly, clean air was pushed through active carbon and silica gel into a chamber by an atmospheric sampling pump (QC-1B, Beijing Municipal Institute of Labour Protection, Beijing, China) at an airflow of $500 \mathrm{~mL} / \mathrm{min}$. Pine needle powder $(150 \mathrm{~g})$ was placed in the chamber, and a trap filter made of glass column and filled with $0.5 \mathrm{~g}$ adsorbent material Porapak $^{\text {Th }} \mathrm{Q}$, 80-100 mesh, Waters, USA) was used to capture the VOCs for $48 \mathrm{~h}$ at room temperature in a second atmospheric sampling pump. Three replicates per sample collected from different sites were conducted simultaneously. Additionally, the trap filters were desorbed by $5 \mathrm{~mL}$ of $\mathrm{n}$-hexane (EMD Millipore, Billerica, MA, USA) and concentrated to $2 \mathrm{~mL}$ under a nitrogen stream. One microliter of sample was analyzed by GCMS (GCMS-QP2010 Ultra, Shimadzu, Kyoto, Japan). In this system, the GC-MS was equipped with an SH-Rxi5Sil MS $(30 \mathrm{~m} \times 0.25 \mathrm{~mm} \times 0.25 \mu \mathrm{m}$, Shimadzu, Kyoto, Japan) and GC column with a carrier gas helium flow of $3.0 \mathrm{~mL} / \mathrm{min}$, and the temperature program was as follows: start at $40^{\circ} \mathrm{C}$, followed by an increase of $3{ }^{\circ} \mathrm{C} / \mathrm{min}$ up to $80^{\circ} \mathrm{C}$ and then an increase of $5^{\circ} \mathrm{C} / \mathrm{min}$ from $80^{\circ} \mathrm{C}$ to $260^{\circ} \mathrm{C}$, and then maintained for $30 \mathrm{~min}$. The mass spectrum was recorded for the mass range $35-500 \mathrm{~m} / \mathrm{z}$ and scanned at a rate of $0.3 \mathrm{~s}$. $\alpha$-Terpineol was identified by GCMS solutions software (Shimadzu, Kyoto, Japan) based on the comparison of its mass spectra (MS) with the NIST14 (National Institute of Standards and Technology) library. In addition, the synthetic standard sample of $\alpha$-terpineol (97\%; J\&K Scientific Ltd., Beijing, China) was analyzed by GC-MS to further verify this VOC by comparing the MS, RT and RI, which were calculated by GCMS solution software.

\section{Measuring the alleviation of NPSF by a-terpineol fumigation}

Consecutively planted soil is the soil that had been planted with $P$. notoginseng for one or more years and showed replant failure. In this study, the consecutively planted soil with a one-year history of $P$. notoginseng cultivation ( $\mathrm{pH}$ : 7.306; electrical conductivity: $597 \mu \mathrm{S}$ / $\mathrm{cm}$; available $\mathrm{N}: 121.45 \mathrm{mg} / \mathrm{kg}$; available P: $158.36 \mathrm{mg} / \mathrm{kg}$; available K: $685.03 \mathrm{mg} / \mathrm{kg}$; Organic matter: $55.33 \mathrm{~g} / \mathrm{kg}$ ) was collected from Xundian County, Yunnan, China $\left(25^{\circ} 31^{\prime} 01.4^{\prime \prime} \mathrm{N}, 103^{\circ} 16^{\prime} 48.9^{\prime \prime} \mathrm{E}\right)$ in 2018 to test the effect of fumigation with $\alpha$-terpineol on NPSF. We transferred $2000 \mathrm{~g}$ of consecutively planted soil to a sealed plastic box in which a sterilized centrifuge tube lid containing $\alpha$-terpineol was then placed to fumigate the soil at concentrations of 0,5 and $50 \mu \mathrm{L} / \mathrm{L}$ (volume of pure $\alpha$ terpineol /volume of the sealed plastic box). The soil treated by steaming for $15 \mathrm{~min}$ at $121^{\circ} \mathrm{C}$ was used as a positive control. The fumigation lasted for 4 weeks, during which the $\alpha$-terpineol was added once a week and the water holding capacity was kept at $30 \%$. After fumigation, $60 \mathrm{~g}$ of fumigated or control soil was transferred to a pot $(4.0 \times 4.0 \times 8.0 \mathrm{~cm})$, and 10 seeds of $P$. notoginseng were sown subsequently. Before sowing, the seeds were surface-disinfected according to Luo's method (Luo et al. 2019). Each treatment included 20 pots and was divided into 5 replicates, and all pots were randomly placed in a greenhouse $\left(25 \pm 2{ }^{\circ} \mathrm{C}, 12 \mathrm{~h}\right.$ light $/ 12 \mathrm{~h}$ dark $)$ and watered once a week to keep the water holding capacity at $30 \%$. After 50 days, the seed decay rate was calculated as follows:

$$
\text { The seed decay rate }(\%)=\frac{\text { Decayed seeds }}{\text { Total seeds in each treatment }} \times 100
$$

\section{Measuring the effects of a-terpineol fumigation on the composition of soil microbiome}

In this experiment, we used divided petri plates for the contactless fumigation of soil consecutively planted with $P$. notoginseng. One compartment of this plate was filled with $10 \mathrm{~g}$ of the abovementioned consecutive soil, and another compartment held a centrifuge tube lid containing $\alpha$-terpineol standard. The plate was sealed with parafilm. The entire experiment lasted for 4 weeks based on a previous study by Yuan et al. (2017). The concentrations of $\alpha$-terpineol fumigation were set at $0,5,20$ and $50 \mu \mathrm{L} / \mathrm{L}$ (volume of pure $\alpha$-terpineol/volume of divided petri plates). During the experiment, $\alpha$-terpineol was added once a week and the water holding capacity of soil was kept at 30\%. All plates, including three replicates of each treatment, were randomly placed in a greenhouse $\left(25 \pm 2{ }^{\circ} \mathrm{C}, 12 \mathrm{~h}\right.$ light $/ 12 \mathrm{~h}$ dark $)$.

\section{Measuring the effects of a-terpineol fumigation on culturable fungi and bacteria in fumigated soil}

Each treatment, which consisted of $10 \mathrm{~g}$ of fumigated soil samples, was divided into two parts: one part was stored at $-80^{\circ} \mathrm{C}$ for subsequent experiments, and the other $5 \mathrm{~g}$ soil sample was used to assess culturable fungi and bacteria on plates as previously reported by Yang et al. (2019). Briefly, a $5 \mathrm{~g}$ soil sample in each treatment was added to $45 \mathrm{~mL}$ of sterilized water. After $15 \mathrm{~min}$ of homogenization, the soil suspension was decimally diluted from $10^{-1}$ to $10^{-7}$, and then $100 \mu \mathrm{L}$ of diluted soil suspension was plated on rose bengal medium (RBM) and nutrient agar (NA) to count fungi and bacteria, respectively (Luo et al. 2019). After incubation at $25^{\circ} \mathrm{C}$ for 4-5 days, the colony forming units (CFU) were counted, 
and the mean values from the counts of four replicates were obtained. The results were expressed as CFU per gram of dry soil. The experiment was repeated three times.

\section{DNA extraction and sequence analysis}

The total DNA of treated soil was extracted from a $0.5 \mathrm{~g}$ soil sample by using the Power Soil ${ }^{\circ}$ DNA Isolation Kit (Mo Bio Laboratories Inc., USA) following the manufacturer's instructions. The quality of the extracted DNA was determined using a spectrophotometer (NanoDrop 2000, Thermo Fisher Scientific, USA). The V4 region of the bacterial 16S rRNA (ribosomal RNA) gene was amplified by primers 515F ( $5^{\prime}$-GTGCCAGCMGCCGCGG TAA-3')-806R(5'-GGACTACHVGGGTWTCTAAT-

$\left.3^{\prime}\right)$, and The ITS2 region of the fungal ITS rRNA gene was amplified with primers ITS3_KYO2(5'-GATGAA GAACGYAGYRAA-3')-ITS4(5' -TCCTCCGCTTATTG ATATGC-3')(Zhou et al. 2019). The amplification products were examined, quantified, and further used to generate sequencing libraries with the TruSeq DNA PCR-Free Sample Prep Kit (Illumina, San Diego, USA). Finally, the fungal ITS and bacterial 16S rRNA genes in the total DNA samples were sequenced using the Illumina Hiseq2500 PE250 platform (Rhonin Biosciences Co., Ltd., Chengdu, China). Raw sequence data were spliced by FLASH, and quality was controlled by Trimmonmatic (Magoč and Salzberg 2011; Bolger et al. 2014). The chimera was further removed using UCHIME (Edgar et al. 2011). The UPARSE algorithm in Usearch 7.1 (http://drive5.com/uparse) was used to cluster the retained effective tags into operational taxonomic units (OTUs) at a 97\% similarity level (Edgar 2013). Taxonomy was assigned based on the UNITE database (ITS) and the SILVA database (16s) through the UCLUST method (Edgar 2010). The data for each sample were processed by normalization based on the minimum data in the sample. Additionally, the Chaol and Simpson indices were calculated to measure the richness and diversity of the microbial community.

\section{Construction and analysis of the microbial network}

In this study, all the microbial networks were constructed at the genus level using Pearson correlation analysis. First of all, the relative abundance of different genera after treated with $\alpha$-terpineol was calculated using Pearson correlation analysis, and only these genera (called 'directly correlated genera') showing statistically significant $(P<0.05)$ linear relationships were selected. To further explore the effects of these directly correlated genera on other microbes, we calculated the Pearson's R between the directly correlated genera and other genera, and only these genera (called 'indirect correlated genera') significantly correlated $(P<0.05$ and Pearson's $|R|>0.6)$ with the directly correlated genera were furtherly used to construct network. The networks were then constructed using Cytoscape version 3.7.0 (Shannon et al. 2003) based on the correlations between the directly correlated genera and $\alpha$-terpineol, as well as between the directly correlated and indirect correlated genera. Finally, the whole co-occurrence network was divided into positive and negative (with $\alpha$-terpineol) networks according to the correlation between the directly correlated genera and increasing concentrations of $\alpha$-terpineol. Likewise, a subnetwork highlighting the soil-borne pathogens of $P$. notoginseng and widely reported PGPRs was constructed. All these networks were visualized in Cytoscape version 3.7.0 (Shannon et al. 2003) and Gephi version 0.9.2 (Bastian et al. 2009). The topological properties of the cooccurrence networks were calculated in Cytoscape by the tool NetworkAnalyzer (Assenov et al. 2008). Regarding the topological properties of these networks, the nodes represent the genera of fungi and bacteria, and the links represent the connections between nodes. Additionally, the degree represents the number of links connected to a node. The clustering coefficient shows the connectedness among nodes in the network. In this study, we calculated the degrees of all nodes in two co-occurrence networks and considered the nodes with higher degrees (Top 10) to be keystone taxa (Hartman et al. 2018), which play key roles in driving community composition and function irrespective of their abundance (Banerjee et al. 2018).

\section{Measuring the effect of a-terpineol on soil-borne pathogens}

Five soil-borne pathogens infecting $P$. notoginseng, including A. panax, I. destructans, F. solani, F. oxysporum and $P$. cactorum, as well as six non-pathogenic fungus that were isolated from consecutively planted soil were selected to validate the antifungal activities of $\alpha$-terpineol by in vitro fumigation. Briefly, a pathogen mycelial block $(6 \mathrm{~mm}$ in diameter) was placed in the middle of a Petri dish filled with PDA (potato dextrose agar). Then, a sterilized centrifuge tube lid containing $\alpha$-terpineol was placed in the bottom of an inverted Petri dish sealed with parafilm. After incubation at $28^{\circ} \mathrm{C}$ for $6-7$ days, the mycelial growth of the pathogen was determined by measuring the colony diameter. Three replicates per treatment were performed with concentrations of $0,10,50,100,200,300$ and $500 \mu \mathrm{L} / \mathrm{L}$ (volume of pure $\alpha$-terpineol/volume of petri plates). The growth inhibition rate was calculated as follows:

The growth inhibition rate $(\%)$
$\quad=\left[\frac{(\text { Radial growth of control-Radial growth of treated sample })}{\text { (Radial growth of control })}\right] \times 100$

The half maximal $(50 \%)$ effective concentrations $\left(\mathrm{EC}_{50}\right)$ were determined according to Förster et al. (2004). 


\section{Measuring the effect of a-terpineol on PGPRs}

To better evaluate the effects of $\alpha$-terpineol on PGPRs, we first isolated bacteria from consecutively planted soil by culturomics with different media: nutrient agar (NA), lysogeny broth (LB), tryptic soy agar (TSA), Reasoner's 2A agar (R2A), and VL55 (Nguyen and Kim 2017). All the isolates were molecularly identified by $16 \mathrm{~S}$ rDNA amplification (Cai et al. 2012), but only those belonging to widely reported PGPRs and showing direct or indirect correlations with $\alpha$-terpineol in the subnetwork were selected for further experiments.

First, the isolates showing direct positive correlations with $\alpha$-terpineol in the network were selected, and the growth promotion effects of $\alpha$-terpineol on them were validated by in vitro fumigation. We used soft agar LB medium (only agar reduced to $0.25 \%$ ) to measure the expansion speed based on the method by Cremer et al. (2019). Briefly, $1 \mu \mathrm{L}\left(10^{6} \mathrm{CFU} / \mathrm{mL}\right)$ of isolate suspension was inoculated in the middle of the soft agar, and the fumigation method was the same as for fungal in vitro fumigation, but the concentrations of $\alpha$-terpineol were reduced to $0,5,10,20$ and $50 \mu \mathrm{L} / \mathrm{L}$. Three replicates per treatment were performed. The growth inhibition rate was calculated as:

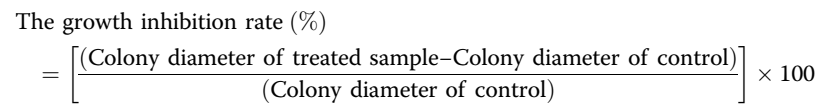

Second, we used V-shaped co-culture experiments to validate the indirect enrichment effects of $\alpha$-terpineol on PGPRs. The synergistic effects of growth promotion between bacteria directly enriched by $\alpha$-terpineol and those indirectly were determined based on the method by Berendsen et al. (2018). Briefly, $1 \mu \mathrm{L}$ of suspension $\left(10^{6}\right.$ $\mathrm{CFU} / \mathrm{mL}$ ) of each of these directly and indirectly enriched bacteria was inoculated five times in a diagonal row of the abovementioned soft agar to create a V-shape of increasingly closer inoculation sites (the distance of two strains was $1.5,2.0,2.5,3.0$ and $3.5 \mathrm{~cm}$ ). Then, the colony diameters were determined.

\section{Measuring the antagonistic activity of bacteria against soil-borne pathogens}

In this experiment, a pathogen mycelial block $(6 \mathrm{~mm}$ in diameter) was placed in the middle of the Petri dish. Then, bacterial suspensions of isolated PGPRs were placed at four sites with the same distance $(25 \mathrm{~mm})$ around the pathogen mycelium block. Pathogens grown alone on PDA plate without PGPR inoculation were used as controls. After 5 days of incubation, the inhibition rates of isolated bacteria on fungal pathogens were calculated as follows:
Inhibition rate $(\%)$
\[ =\left[\frac{(\text { Diameter of control-Antimicrobial band width of treated sample })}{(\text { Diameter of control })}\right] \times 100 \]

\section{Statistical analysis}

IBM SPSS Statistics version 25 (SPSS Inc., Chicago, Illinois, USA) was used for general statistical analyses. One-way analysis of variance (ANOVA) and Duncan's multiple range test $(P<0.05)$ were used to analyze the mean separation among treatments. Pearson's correlation coefficient was employed to correlate the relative abundance of microbes at the genus level with increasing concentrations of $\alpha$-terpineol. The Chao1 and Simpson indices were calculated using $\mathrm{R}$ software (vegan package). Principal coordinate analysis (PCoA) based on the Bray-Curtis distance was performed by $\mathrm{R}$ software (APE package). Some data analyses are described in the corresponding sections above.

\section{Abbreviations}

CFU: Colony forming units; $\mathrm{EC}_{50}$ : Effective concentration for $50 \%$ inhibition; GC-MS: Gas chromatography-mass spectrometry; LB: Lysogeny broth; MS: Mass spectra; NA: Nutrient agar; NIST: National Institute of Standards and Technology; NPSFs: Negative plant-soil feedbacks; OTU: Operational taxonomic units; PCoA: Principal coordinates analysis; PDA: Potato dextrose agar; PGPRs: Plant growth-promoting rhizobacteria; PSFs: Plant-soil feedbacks; R2A: Reasoner's 2A agar; Rl: Retention index; RT: Retention time;

SAR: Systemic acquired resistance; TSA: Tryptic soy agar; VOC: Volatile organic compounds

\section{Supplementary Information}

The online version contains supplementary material available at https://doi. org/10.1186/s42483-021-00090-1.

Additional file 1: Table S1. Processed sample data used to analyze the fungal community. Table S2. Processed sample data used to analyze the bacterial community. Table S3. Correlation between a-terpineol and the relative abundance of fungi or bacteria at the phylum level. Table S4. Widely reported PGPRs in agricultural system. Table S5. Twenty-three fungal isolates from Panax notoginseng field soil. Table S6. One hundred and eighty-nine bacterial isolates from Panax notoginseng field soil. Table S7. Bacterial isolates used for co-culture and antagonistic experiments.

Additional file 2: Figure S1. Heat map illustrating that the high abundance of Escherichia-Shigella overshadowed the remaining bacterial microbial community at the genus level. Figure S2. Effect of the removal of Escherichia-Shigella reads on bacterial community beta diversity. Figure S3. Effects of 4 weeks of a-terpineol fumigation on the alpha-diversity indices of fungal and bacterial communities in soil consecutively planted with Panax notoginseng. Figure S4. Effects of aterpineol on the growth of non-pathogenic fungus of Panax notoginseng.

Acknowledgments

Not applicable.

Authors' contributions

$\mathrm{HH}, \mathrm{SZ}, \mathrm{YYZ}$ and $\mathrm{XH}$ conceived and designed the experiments. $\mathrm{CY}, \mathrm{YL}, J Z, T L$, YJZ and CG carried out the experiments. CY analyzed the data. CY, YL, HH, MY and SZ wrote the manuscript. All authors read and approved the final manuscript.

\section{Funding}

This work was partially funded by the Major Science and Technology Project in Yunnan Province of China (no. 202001BB050001), the National Key 
Research and Development Program of China (2017YFC1702502 and 2018YFD0201107), the Young and Middle-aged Academic and Technical Leaders Reserve Programme in Yunnan Province (202005 AC160045), the Yunnan Ten Thousand Talents Plan Young \& Elite Talents Project, the Yunnan Provincial Key Programs of Yunnan Eco-friendly Food International Cooperation Research Center Project (2019ZG00901), the Central Government Guides Local Science and Technology Development Funds (202107AA110004).

\section{Availability of data and materials}

Raw sequencing data are accessible under NCBI BioProject ID: PRJNA639436.

\section{Declarations}

\section{Ethics approval and consent to participate}

Not applicable.

\section{Consent for publication}

Not applicable.

\section{Competing interests}

The authors declare that they have no competing interests.

\section{Author details}

${ }^{1}$ State Key Laboratory for Conservation and Utilization of Bio-Resources in Yunnan, Yunnan Agricultural University, Kunming 650201, China. ${ }^{2}$ Key Laboratory for Agro-biodiversity and Pest Control of Ministry of Education, Yunnan Agricultural University, Kunming 650201, China. ${ }^{3}$ College of Plant Protection, Yunnan Agricultural University, Kunming 650201, China. ${ }^{4}$ School of Agriculture, Yunnan University, Kunming 650091, China. ${ }^{5}$ School of Landscape and Horticulture, Southwest Forestry University, Kunming 650233, China.

Received: 11 January 2021 Accepted: 3 June 2021

Published online: 29 June 2021

\section{References}

Agler MT, Ruhe J, Kroll S, Morhenn C, Kim ST, Weigel D, et al. Microbial hub taxa link host and abiotic factors to plant microbiome variation. PLoS Biol. 2016: 14(1):e1002352. https://doi.org/10.1371/journal.pbio.1002352.

Alphei J, Scheu S. Effects of biocidal treatments on biological and nutritional properties of a mull-structured woodland soil. Geoderma. 1993;56(1-4):43548. https://doi.org/10.1016/0016-7061(93)90125-5.

Arnault I, Fleurance C, Vey F, Du Fretay G, Auger J. Use of Alliaceae residues to control soil-borne pathogens. Ind Crop Prod. 2013;49:265-72. https://doi. org/10.1016/j.indcrop.2013.05.007.

Assenov Y, Ramirez F, Schelhorn SE, Lengauer T, Albrecht M. Computing topological parameters of biological networks. Bioinformatics. 2008;24(2): 282-4. https://doi.org/10.1093/bioinformatics/btm554.

Bahram M, Hildebrand F, Forslund SK, Anderson JL, Soudzilovskaia NA, Bodegom PM, et al. Structure and function of the global topsoil microbiome. Nature. 2018;560(7717):233-7. https://doi.org/10.1038/s41586-018-0386-6.

Banerjee S, Schlaeppi K, van der Heijden MGA. Keystone taxa as drivers of microbiome structure and functioning. Nat Rev Microbiol. 2018;16(9):567-76. https://doi.org/10.1038/s41579-018-0024-1.

Banerjee S, Walder F, Buchi L, Meyer M, Held AY, Gattinger A, et al. Agricultural intensification reduces microbial network complexity and the abundance of keystone taxa in roots. ISME J. 2019;13(7):1722-36. https://doi.org/10.1038/ s41396-019-0383-2

Bastian M, Heymann S, Jacomy M. Gephi: an open source software for exploring and manipulating networks. San Jose: Proceeding of the Third international AAAI conference on weblogs and social media. ICWSM 2009; 2009.

Bennett JA, Klironomos J. Mechanisms of plant-soil feedback: interactions among biotic and abiotic drivers. New Phytol. 2019;222(1):91-6. https://doi.org/1 0.1111/nph.15603.

Bennett JA, Maherali H, Reinhart KO, Lekberg Y, Hart MM, Klironomos J. Plant-soil feedbacks and mycorrhizal type influence temperate forest population dynamics. Science. 2017:355(6321):181-4. https://doi.org/10.1126/science.aai8212.

Berendsen RL, Vismans G, Yu K, Song Y, de Jonge R, Burgman WP, et al. Diseaseinduced assemblage of a plant-beneficial bacterial consortium. ISME J. 2018; 12(6):1496-507. https://doi.org/10.1038/s41396-018-0093-1.
Berhal C, De Clerck C, Fauconnier ML, Levicek C, Boullis A, Kaddes A, et al. First characterisation of volatile organic compounds emitted by banana plants. Sci Rep. 2017;7(1):46400. https://doi.org/10.1038/srep46400.

Besharati $\mathrm{H}$. Effects of sulfur application and Thiobacillus inoculation on soil nutrient availability, wheat yield and plant nutrient concentration in calcareous soils with different calcium carbonate content. J Plant Nutr. 2017; 40(3):447-56. https://doi.org/10.1080/01904167.2016.1245326.

Bolger AM, Lohse M, Usadel B. Trimmomatic: a flexible trimmer for Illumina sequence data. Bioinformatics. 2014;30(15):2114-20. https://doi.org/10.1093/ bioinformatics/btu170.

Cai Z, Chen Q, Wang H, He Y, Wang W, Zhao X, et al. Degradation of the novel herbicide ZJ0273 by Amycolatopsis sp. M3-1 isolated from soil. Appl Microbiol Biotechnol. 2012;96(5):1371-9. https://doi.org/10.1007/s00253-011-3867-1.

Cha JY, Han S, Hong HJ, Cho H, Kim D, Kwon Y, et al. Microbial and biochemical basis of a Fusarium wilt-suppressive soil. ISME J. 2016:10(1):119-29. https:// doi.org/10.1038/ismej.2015.95

Chen H, Zhao S, Zhang K, Zhao J, Jiang J, Chen F, et al. Evaluation of soil-applied chemical fungicide and biofungicide for control of the Fusarium wilt of chrysanthemum and their effects on rhizosphere soil microbiota. Agriculture. 2018;8(12):184. https://doi.org/10.3390/agriculture8120184.

Chen Y, Weng Y, Zhou M, Meng Y, Liu J, Yang L, et al. Linalool-and a-terpineolinduced programmed cell death in Chlamydomonas reinhardtii. Ecotoxicol Environ Saf. 2019;167:435-40. https://doi.org/10.1016/j.ecoenv.2018.10.062.

Cremer J, Honda T, Tang Y, Wong-Ng J, Vergassola M, Hwa T. Chemotaxis as a navigation strategy to boost range expansion. Nature. 2019;575(7784):658-63. https://doi.org/10.1038/s41586-019-1733-y.

D'Souza G, Shitut S, Preussger D, Yousif G, Waschina S, Kost C. Ecology and evolution of metabolic cross-feeding interactions in bacteria. Nat Prod Rep. 2018;35(5):455-88. https://doi.org/10.1039/C8NP00009C.

Durán P, Thiergart T, Garrido-Oter R, Agler M, Kemen E, Schulze-Lefert P, et al. Microbial interkingdom interactions in roots promote Arabidopsis survival. Cell. 2018;175:973-83.e14.

Edgar RC. Search and clustering orders of magnitude faster than BLAST. Bioinformatics. 2010;26(19):2460-1. https://doi.org/10.1093/bioinformatics/bta461.

Edgar RC. UPARSE: highly accurate OTU sequences from microbial amplicon reads. Nat Methods. 2013;10(10):996-8. https://doi.org/10.1038/nmeth.2604.

Edgar RC, Haas BJ, Clemente JC, Quince C, Knight R. UCHIME improves sensitivity and speed of chimera detection. Bioinformatics. 2011:27(16):2194-200. https://doi.org/10.1093/bioinformatics/btr381.

Eichorst SA, Kuske CR, Schmidt TM. Influence of plant polymers on the distribution and cultivation of bacteria in the phylum Acidobacteria. Appl Environ Microbiol. 2011;77(2):586-96. https://doi.org/10.1128/AEM.01080-10.

El-Azeem SAM, Mehana TA, Shabayek AA. Some plant growth promoting traits of rhizobacteria isolated from Suez Canal region. Egypt African Crop Sci Confer Proc. 2007:8:1517-25

Fennimore SA, Martin FN, Miller TC, Broome JC, Dorn N, Greene I. Evaluation of a mobile steam applicator for soil disinfestation in California strawberry. HortScience. 2014;49(12):1542-9. https://doi.org/10.21273/ HORTSCI.49.12.1542.

Finkel OM, Salas-González I, Castrillo G, Law TF, Conway JM, Jones CD, et al. Root development is maintained by specific bacteria-bacteria interactions within a complex microbiome. BioRxiv. 2019. https://doi.org/10.1101/645655.

Förster $\mathrm{H}$, Kanetis $\mathrm{L}$, Adaskaveg JE. Spiral gradient dilution, a rapid method for determining growth responses and 50\% effective concentration values in fungus-fungicide interactions. Phytopathology. 2004;94(2):163-70. https://doi. org/10.1094/PHYTO.2004.94.2.163.

Gimsing AL, Kirkegaard JA. Glucosinolate and isothiocyanate concentration in soil following incorporation of Brassica biofumigants. Soil Biol Biochem. 2006 38(8):2255-64. https://doi.org/10.1016/j.soilbio.2006.01.024.

Gómez Expósito R, de Bruijn I, Postma J, Raaijmakers JM. Current insights into the role of rhizosphere bacteria in disease suppressive soils. Front Microbiol. 2017:8:2529. https://doi.org/10.3389/fmicb.2017.02529.

Gurtler JB. Pathogen decontamination of food crop soil: a review. J Food Prot. 2017:80(9):1461-70. https://doi.org/10.4315/0362-028X.JFP-17-040.

Hammer KA, Carson CF, Riley TV. Antifungal activity of the components of Melaleuca alternifolia (tea tree) oil. J Appl Microbiol. 2003;95(4):853-60. https://doi.org/10.1046/j.1365-2672.2003.02059.x.

Hartman K, van der Heijden MGA, Wittwer RA, Banerjee S, Walser J-C, Schlaeppi K. Cropping practices manipulate abundance patterns of root and soil microbiome members paving the way to smart farming. Microbiome. 2018; 6(1):14. https://doi.org/10.1186/s40168-017-0389-9. 
Hassani MA, Durán P, Hacquard S. Microbial interactions within the plant holobiont. Microbiome. 2018;6(1):58. https://doi.org/10.1186/s40168-018-0445-0.

Huang LF, Song LX, Xia XJ, Mao WH, Shi K, Zhou YH, et al. Plant-soil feedbacks and soil sickness: from mechanisms to application in agriculture. J Chem Ecol. 2013;39(2):232-42. https://doi.org/10.1007/s10886-013-0244-9.

Ibekwe AM, Papiernik SK, Gan J, Yates SR, Yang CH, Crowley DE. Impact of fumigants on soil microbial communities. Appl Environ Microbiol. 2001;67(7): 3245-57. https://doi.org/10.1128/AEM.67.7.3245-3257.2001.

Jin N, Lu X, Wang X, Liu Q, Peng D, Jian $H$. The effect of combined application of Streptomyces rubrogriseus HDZ-9-47 with soil biofumigation on soil microbial and nematode communities. Sci Rep. 2019;9(1):16886. https://doi. org/10.1038/s41598-019-52941-9.

Katan J. Physical and cultural methods for the management of soil-borne pathogens. Crop Prot. 2000;19(8-10):725-31. https://doi.org/10.1016/S0261-21 94(00)00096-X

Kim Y-S, Shin D-H. Volatile components and antibacterial effects of pine needle (Pinus densiflora S. and Z.) extracts. Food Microbiol. 2005;22(1):37-45. https://doi.org/10.1016/j.fm.2004.05.002.

Klose S, Acosta-Martínez V, Ajwa HA. Microbial community composition and enzyme activities in a sandy loam soil after fumigation with methyl bromide or alternative biocides. Soil Biol Biochem. 2006;38(6):1243-54. https://doi. org/10.1016/j.soilbio.2005.09.025.

Kulmatiski A, Beard KH, Stevens JR, Cobbold SM. Plant-soil feedbacks: a metaanalytical review. Ecol Lett. 2008;11(9):980-92. https://doi.org/10.1111/j.14610248.2008.01209.x

Kumar A, Azad CS, Kumar R, Kumar R, Imran M. Soil Solarization: an eco-friendly and effective disease management approach for soil borne diseases. J Pharmacogn Phytochem. 2017;6(6S):513-5.

Lankau RA, Wheeler E, Bennett AE, Strauss SY. Plant-soil feedbacks contribute to an intransitive competitive network that promotes both genetic and species diversity. J Ecol. 2011;99(1):176-85. https://doi.org/10.1111/j.1365-2745.2010. 01736.x.

Latz E, Eisenhauer N, Rall BC, Allan E, Roscher C, Scheu S, et al. Plant diversity improves protection against soil-borne pathogens by fostering antagonistic bacterial communities. J Ecol. 2012;100(3):597-604. https://doi.org/10.1111/ j.1365-2745.2011.01940.x.

Le Cointe R, Simon TE, Delarue P, Hervé M, Leclerc M, Poggi S. Reducing the use of pesticides with site-specific application: the chemical control of Rhizoctonia solani as a case of study for the management of soil-borne diseases. PLoS One. 2016;11(9):e0163221. https://doi.org/10.1371/journal.pone.0163221.

Lembright HW. Soil fumigation: principles and application technology. J Nematol. 1990;22(4S):632-44.

Li Y, Wang B, Chang Y, Yang Y, Yao C, Huang X, et al. Reductive soil disinfestation effectively alleviates the replant failure of Sanqi ginseng through allelochemical degradation and pathogen suppression. Appl Microbiol Biotechnol. 2019;103(8):3581-95. https://doi.org/10.1007/s00253-019-09676-4.

Little AEF, Robinson CJ, Peterson SB, Raffa KF, Handelsman J. Rules of engagement: interspecies interactions that regulate microbial communities. Annu Rev Microbiol. 2008;62(1):375-401. https://doi.org/10.1146/annurev. micro.030608.101423.

Liu H, Yang M, Zhu S. Strategies to solve the problem of soil sickness of Panax notoginseng (family: Araliaceae). Allelopath J. 2019;47(1):37-56. https://doi. org/10.26651/allelo.j/2019-47-1-1218.

Loqman S, Barka EA, Clément C, Ouhdouch Y. Antagonistic actinomycetes from Moroccan soil to control the grapevine gray mold. World J Microbiol Biotechnol. 2009;25(1):81-91. https://doi.org/10.1007/s11274-008-9864-6.

Luo L, Guo C, Wang L, Zhang J, Deng L, Luo K, et al. Negative plant-soil feedback driven by re-assemblage of the rhizosphere microbiome with the growth of Panax notoginseng. Front Microbiol. 2019;10:1597. https://doi.org/10.3389/ fmicb.2019.01597.

Magoč T, Salzberg SL. FLASH: fast length adjustment of short reads to improve genome assemblies. Bioinformatics. 2011;27(21):2957-63. https://doi.org/10.1 093/bioinformatics/btr507.

Mangan SA, Schnitzer SA, Herre EA, Mack KM, Valencia MC, Sanchez El, et al. Negative plant-soil feedback predicts tree-species relative abundance in a tropical forest. Nature. 2010;466(7307):752-5. https://doi.org/10.1038/na ture09273.

Mao Z, Long Y, Zhu Y, Zhu S, He X, Chen Z. First report of Cylindrocarpon destructans var. destructans causing black root rot of sanqi (Panax notoginseng) in China. Plant Dis. 2014:98(1):162. https://doi.org/10.1094/ PDIS-11-12-1104-PDN
Mendes LW, Mendes R, Raaijmakers JM, Tsai SM. Breeding for soil-borne pathogen resistance impacts active rhizosphere microbiome of common bean. ISME J. 2018;12(12):3038-42. https://doi.org/10.1038/s41396-0180234-6.

Mendes R, Kruijt M, de Bruijn I, Dekkers E, van der Voort M, Schneider JHM, et al. Deciphering the rhizosphere microbiome for disease-suppressive bacteria. Science. 2011;332(6033):1097-100. https://doi.org/10.1126/science.1203980.

Miao Z, Li S, Liu X, Chen Y, Li Y, Wang Y, et al. The causal microorganisms of Panax notoginseng root rot disease. Sci Agric Sin. 2006;39(7):1371-8 https:// www.chinaagrisci.com/CN/Y2006/N39/17/1371.

Miguel A, Maroto JV, San Bautista A, Baixauli C, Cebolla V, Pascual B, et al. The grafting of triploid watermelon is an advantageous alternative to soil fumigation by methyl bromide for control of Fusarium wilt. Sci Hortic. 2004; 103(1):9-17. https://doi.org/10.1016/j.scienta.2004.04.007.

Mishra A, Chauhan PS, Chaudhry V, Tripathi M, Nautiyal CS. Rhizosphere competent Pantoea agglomerans enhances maize (Zea mays) and chickpea (Cicer arietinum L.) growth, without altering the rhizosphere functional diversity. Antonie Van Leeuwenhoek. 2011;100(3):405-13. https://doi.org/10.1 007/s10482-011-9596-8.

Nguyen TM, Kim J. Azohydromonas riparia sp. nov. and Azohydromonas ureilytica sp. nov. isolated from a riverside soil in South Korea. J Microbiol. 2017;55(5): 330-6. https://doi.org/10.1007/s12275-017-6519-z.

Nuñez-Zofío M, Larregla S, Garbisu C. Repeated biodisinfection controls the incidence of Phytophthora root and crown rot of pepper while improving soil quality. Span J Agric Res. 2012;10(3):794-805. https://doi.org/10.5424/sja r/2012103-571-11.

Omirou M, Rousidou C, Bekris F, Papadopoulou KK, Menkissoglou-Spiroudi U, Ehaliotis $C$, et al. The impact of biofumigation and chemical fumigation methods on the structure and function of the soil microbial community. Microb Ecol. 2011;61(1):201-13. https://doi.org/10.1007/s00248-010-9740-4.

Park JS, Lee GH. Volatile compounds and antimicrobial and antioxidant activities of the essential oils of the needles of Pinus densiflora and Pinus thunbergii. J Sci Food Agric. 2011;91(4):703-9. https://doi.org/10.1002/jsfa.4239.

Park MJ, Gwak KS, Yang I, Kim KW, Jeung EB, Chang JW, et al. Effect of citral, eugenol, nerolidol and a-terpineol on the ultrastructural changes of Trichophyton mentagrophytes. Fitoterapia. 2009;80(5):290-6. https://doi.org/1 0.1016/j.fitote.2009.03.007.

Pii Y, Mimmo T, Tomasi N, Terzano R, Cesco S, Crecchio C. Microbial interactions in the rhizosphere: beneficial influences of plant growth-promoting rhizobacteria on nutrient acquisition process. A review. Biol Fertil Soils. 2015; 51(4):403-15. https://doi.org/10.1007/s00374-015-0996-1.

Pinto E, Gonçalves MJ, Oliveira P, Coelho J, Cavaleiro C, Salgueiro L. Activity of Thymus caespititius essential oil and a-terpineol against yeasts and filamentous fungi. Ind Crop Prod. 2014;62:107-12. https://doi.org/10.1016/j. indcrop.2014.08.004.

Podio NS, Guzman CA, Meriles JM. Microbial community structure in a silty clay loam soil after fumigation with three broad spectrum fungicides. I Environ Sci Health B. 2008;43(4):333-40. https://doi.org/10.1080/0360123 0801941675.

Politeo O, Skocibusic M, Maravic A, Ruscic M, Milos M. Chemical composition and antimicrobial activity of the essential oil of endemic Dalmatian black pine (Pinus nigra ssp. dalmatica). Chem Biodivers. 2011;8(3):540-7. https://doi.org/1 $0.1002 / c b d v .201000185$

Riedlmeier M, Ghirardo A, Wenig M, Knappe C, Koch K, Georgii E, et al. Monoterpenes support systemic acquired resistance within and between plants. Plant Cell. 2017;29(6):1440-59. https://doi.org/10.1105/tpc.16.00898.

Sathya A, Vijayabharathi R, Gopalakrishnan S. Plant growth-promoting actinobacteria: a new strategy for enhancing sustainable production and protection of grain legumes. 3. Biotech. 2017;7:102.

Schalchli H, Tortella GR, Rubilar O, Parra L, Hormazabal E, Quiroz A. Fungal volatiles: an environmentally friendly tool to control pathogenic microorganisms in plants. Crit Rev Biotechnol. 2016;36(1):144-52. https://doi. org/10.3109/07388551.2014.946466.

Shannon P, Markiel A, Ozier O, Baliga NS, Wang JT, Ramage D, et al. Cytoscape: a software environment for integrated models of biomolecular interaction networks. Genome Res. 2003;13(11):2498-504. https://doi.org/10.1101/gr.1239303.

Siegel-Hertz K, Edel-Hermann V, Chapelle E, Terrat S, Raaijmakers JM, Steinberg C. Comparative microbiome analysis of a Fusarium wilt suppressive soil and a Fusarium wilt conducive soil from the chateaurenard region. Front Microbiol. 2018;9:568. https://doi.org/10.3389/fmicb.2018.00568. 
Ucar G, Balaban M. Volatile needle extractives of Anatolian black pine varieties: P. nigra subsp. pallasiana var. pallasiana and var. pyramidata. Biochem Syst Ecol. 2004;32(11):983-92. https://doi.org/10.1016/j.bse.2004.02.006.

Ullah I, Jilani G, UI Haq MI, Khan A. Enhancing bio-available phosphorous in soil through sulfur oxidation by Thiobacilli. Br Microbiol Res J. 2013;3(3):378-92. https://doi.org/10.9734/BMRJ/2013/4063.

Vejan P, Abdullah R, Khadiran T, Ismail S, Nasrulhaq BA. Role of plant growth promoting rhizobacteria in agricultural sustainability - a review. Molecules. 2016;21(5):573. https://doi.org/10.3390/molecules21050573.

Wang $Q$, Ma Y, Yang H, Chang Z. Effect of biofumigation and chemical fumigation on soil microbial community structure and control of pepper Phytophthora blight. World J Microbiol Biotechnol. 2014;30(2):507-18. https:// doi.org/10.1007/s11274-013-1462-6.

Wei W, Yang M, Liu Y, Huang H, Ye C, Zheng J, et al. Fertilizer $\mathrm{N}$ application rate impacts plant-soil feedback in a sanqi production system. Sci Total Environ. 2018;633:796-807. https://doi.org/10.1016/j.scitotenv.2018.03.219.

Wei Z, Gu Y, Friman VP, Kowalchuk GA, Xu Y, Shen Q, et al. Initial soil microbiome composition and functioning predetermine future plant health. Sci Adv. 2019;5:eaaw0759.

Yang M, Chuan Y, Guo C, Liao J, Xu Y, Mei X, et al. Panax notoginseng root cell death caused by the autotoxic ginsenoside $\mathrm{Rg} 1$ is due to over-accumulation of ROS, as revealed by transcriptomic and cellular approaches. Front Plant Sci. 2018a;9:264. https://doi.org/10.3389/fpls.2018.00264.

Yang M, Huang C, Xue Y, Li S, Lu L, Wang C. Biofumigation with volatile organic compounds from Streptomyces alboflavus TD-1 and pure chemicals to control Aspergillus ochraceus. Ann Appl Biol. 2018b;173(3):313-22. https://doi. org/10.1111/aab.12465.

Yang M, Yuan Y, Huang H, Ye C, Guo C, Xu Y, et al. Steaming combined with biochar application eliminates negative plant-soil feedback for sanqi cultivation. Soil Tillage Res. 2019;189:189-98. https://doi.org/10.1016/j.still.201 9.02.006.

Yang M, Zhang X, Xu Y, Mei X, Jiang B, Liao J, et al. Autotoxic ginsenosides in the rhizosphere contribute to the replant failure of Panax notoginseng. PLoS One. 2015;10(2):e0118555. https://doi.org/10.1371/journal.pone.0118555.

Ye C, Fang H, Liu H, Yang M, Zhu S. Current status of soil sickness research on Panax notoginseng in Yunnan, China. Allelopath J. 2019;47(1):1-14. https:// doi.org/10.26651/allelo.j/2019-47-1-1216.

Yuan J, Raza W, Shen Q, Huang Q. Antifungal activity of Bacillus amyloliquefaciens NJN-6 volatile compounds against Fusarium oxysporum f. sp. cubense. Appl Environ Microbiol. 2012;78(16):5942-4. https://doi.org/10.1128/AEM.01357-12.

Yuan J, Zhao M, Li R, Huang Q, Raza W, Rensing C, et al. Microbial volatile compounds alter the soil microbial community. Environ Sci Pollut Res. 2017; 24(28):22485-93. https://doi.org/10.1007/s11356-017-9839-y.

Zhang D, Yan D, Cheng H, Fang W, Huang B, Wang X, et al. Effects of multi-year biofumigation on soil bacterial and fungal communities and strawberry yield. Environ Pollut. 2020;256:113415. https://doi.org/10.1016/j.envpol.2019.113415.

Zheng Y. Antibiotic functions and volatile organic compounds from Pinus tabulaeformis var. mukdensis Uyeki and Betula platyphlla SukNortheast Forestry University Harbin, China; 2008.

Zhou H, Tao N, Jia L. Antifungal activity of citral, octanal and a-terpineol against Geotrichum citri-aurantii. Food Control. 2014;37:277-83. https://doi.org/10.101 6/j.foodcont.2013.09.057.

Zhou Z, Gao T, Van Zwieten L, Zhu Q, Yan T, Xue J, et al. Soil microbial community structure shifts induced by biochar and biochar-based fertilizer amendment to karst calcareous soil. Soil Sci Soc Am J. 2019;83(2):398-408. https://doi.org/10.2136/sssaj2018.08.0297.

Ready to submit your research? Choose BMC and benefit from:

- fast, convenient online submission

- thorough peer review by experienced researchers in your field

- rapid publication on acceptance

- support for research data, including large and complex data types

- gold Open Access which fosters wider collaboration and increased citations

- maximum visibility for your research: over $100 \mathrm{M}$ website views per year

At BMC, research is always in progress.

Learn more biomedcentral.com/submissions 